\title{
The acute exercise-cognition interaction: From the catecholamines hypothesis to an interoception model
}

\author{
Terry McMorris \\ Institute of Sport, University of Chichester, College Lane, Chichester, West Sussex PO19 6PE, United Kingdom \\ Department of Sport and Exercise Science, Faculty of Science, University of Portsmouth, Guildhall Walk, Portsmouth PO1 2ER, United Kingdom
}

\section{A R T I C L E I N F O}

\section{Keywords:}

Anterior cingulate cortex

Insula cortex

Effort cost

Locus coeruleus

Motivation

Orbitofrontal cortex

\begin{abstract}
A B S T R A C T
An interoception model for the acute exercise-cognition interaction is presented. During exercise following the norepinephrine threshold, interoceptive feedback induces increased tonic release of extracellular catecholamines, facilitating phasic release hence better cognitive performance of executive functions. When exercise intensity increases to maximum, the nature of task-induced norepinephrine release from the locus coeruleus is dependent on interaction between motivation, perceived effort costs and perceived availability of resources. This is controlled by interaction between the rostral and dorsolateral prefrontal cortices, orbitofrontal cortex, anterior cingulate cortex and anterior insula cortex. If perceived available resources are sufficient to meet predicted effort costs and reward value is high, tonic release from the locus coeruleus is attenuated thus facilitating phasic release, therefore cognition is not inhibited. However, if perceived available resources are insufficient to meet predicted effort costs or reward value is low, tonic release from the locus coeruleus is induced, attenuating phasic release. As a result, cognition is inhibited, although long-term memory and tasks that require switching to new stimuli-response couplings are probably facilitated.
\end{abstract}

\section{Introduction}

Although early research into the acute exercise-cognition interaction was atheoretical (see McMorris, 2016a, for a review), Davey (1973) found that moderate intensity exercise induced better performance than that at rest and during vigorous exercise, which did not differ from one another. This led Cooper (1973) to hypothesize that exercise affects arousal levels in the same way as other stressors and induces an inverted-U effect on performance, as had been demonstrated by Yerkes and Dodson (1908) in mice. Soon, models of stress and performance, such as Kahneman's (1973) Allocation of Resources Theory and Sanders' (1983) cognitive-energetic theory, gained popularity as rationales for acute exercise-cognition interaction research (see Audiffren, 2009, for an excellent review). At the same time, the roles of the catecholamines, dopamine, norepinephrine and epinephrine, in arousal and stress were being examined in animals (Gordon et al., 1966; Reis and Fuxe, 1968, 1969). Therefore, Cooper (1973) proffered the catecholamines hypothesis for an acute exercise-cognition interaction effect. Since then, Chmura et al. (1994), and my colleagues and I (McMorris, 2009, 2016b; McMorris et al., 2016) have elaborated on this hypothesis. However, while empirical support for the hypothesis is sound for the effects of moderate intensity exercise, it is very weak with regard to the effects of higher intensities of exercise.

Narrative reviews (Best, 2010; McMorris, 2016b; Tomporowski, 2003) and meta-analyses (Chang et al., 2012; Lambourne and Tomporowski, 2010; McMorris and Hale, 2012) have found only limited evidence for an inverted-U effect. More recent empirical research into the inverted-U effect fails to clarify the picture, with somewhat equivocal results being demonstrated (Chang et al., 2019; Ligeza et al., 2018; Smith et al., 2016). Although the inverted-U effect has limited support, the reviews provide strong evidence for an improvement in cognitive performance from rest to moderate intensity exercise, The findings of studies carried out since these reviews have generally provided more equivocal results with some showing facilitation during and after moderate intensity exercise (Bae and Masaki, 2019; Chang et al., 2019; González-Fernández et al., 2017; Hsieh et al., 2018; Kujach et al., 2018; Labban and Etnier, 2018; Wu et al., 2019) but not others (Chacko et al., 2019; Hill et al., 2019; Lefferts et al., 2019; Winneke et al., 2019). Overall, however, there remains strong support for the conclusion that moderate intensity exercise facilitates performance. This is especially so for studies where the catecholamines thresholds or the ventilatory threshold were used as the criteria for determining what constitutes

\footnotetext{
* 63 Four Winds Court, Hartlepool TS26 0LP, United Kingdom.

E-mail address: t.mcmorris@chi.ac.uk.
} 
moderate intensity (McMorris and Hale, 2015).

Before going any further, it is important to note that the outline of the reviews, reported above, ignores a number of issues with the timing of the cognitive tasks. Undertaking a cognitive task at rest is not the same as doing it while simultaneously exercising, which is a dual task. Lambourne and Tomporowski (2010) demonstrated higher effect sizes when cognition was measured post-exercise rather than during exercise. However, Chang et al. (2012) showed that effect sizes were very similar when testing took place during, immediately following and after an extended interval. Neither set of authors carried out statistical analyses between the moderators. McMorris and Hale (2012) did undertake statistical analyses and found no significant differences in effect sizes obtained during compared to following exercise. Furthermore, Joyce et al. (2009) demonstrated statistically significant effects, even when testing took place 50 mins after exercise. This is not surprising as, although the half-life of catecholamines in the periphery is $<2 \mathrm{~min}$. (Peaston and Weinkove, 2004), in the brain it is in the range of 8-12 h (Eisenhofer et al., 2004). However, this does not mean that the processes are not different, a point which is made in the proposed model. Moreover, the model presents a rationale for a lack of differences in the results despite the processes differing.

While we can say with some confidence that there is a positive effect of moderate intensity exercise, of short to moderate duration, on cognition, the situation is less clear with high intensities of exercise. McMorris (2016b) found that results for exercise $>80 \%$ maximum volume of oxygen uptake $\left(\mathrm{VO}_{2 \mathrm{MAx}}\right)$ or equivalents (see Arts and Kuipers, 1994, for determining equivalents), were equivocal except for autonomous tasks, which demonstrated a positive effect. Bergstrom et al. (2013) classified this exercise intensity as being "severe" (p. 233). Longterm memory (LTM) tasks also showed unequivocal positive effects following severe exercise but there were only two studies (Griffin et al., 2011; Winter et al., 2007). Research carried out since the McMorris (2016b) review fails to clarify the position, with facilitation shown by some (Finkenzeller et al., 2018; Hashimoto et al., 2018; Wohlwend et al., 2017), non-significance by others (Bediz et al., 2016; Finkenzeller et al., 2018; Hashimoto et al., 2018; Sudo et al., 2017). While Tempest et al. (2017) demonstrated facilitation of speed of response but inhibition of accuracy.

The evidence outlined above undoubtedly casts doubt on the efficacy of the catecholamines hypothesis, certainly with regard to severe exercise. Moreover, theories of central fatigue (Marcora, 2009; McMorris et al., 2018a; Noakes et al., 2004) and the effect of mental fatigue on subsequent exercise (see Brown et al., 2020; McMorris et al., 2018b; Van Cutsem et al., 2017, for reviews) introduce factors which have not been applied to acute exercise-catecholamines-cognition interaction research but which may help to explain the equivocal data. In particular, the role of interoceptive feedback in these effects (Hilty et al., 2011; McMorris et al., 2018a; Robertson and Marino, 2016) would appear to apply to the the acute exercise-cognition interaction. Modern interpretations of interoception (Craig, 2002, 2015; Damasio, 1994) especially lead one to consider psychological factors such as motivation and its interaction with perception of effort costs (see Aston-Jones and Cohen, 2005). Therefore, in this article an interoception model to explain how acute exercise affects cognition is presented. In this model, it is suggested that the positive effects of moderate intensity exercise depend on exerciseinduced release of norepinephrine from the locus coeruleus, and subsequent release of dopamine from the ventral tegmental area and substantia nigra pars compacta increasing extracellular catecholamines in brain regions responsible for cognition. This is consistent with the catecholamines hypothesis. However, it is proposed that when exercise intensity increases to that inducing central fatigue, tonic locus coeruleus-norepinephrine release is increased, which affects the taskinduced phasic norepinephrine release, thus modulating performance of tasks requiring responses to salient stimuli. These effects are dependent on interactions between motivation, perceived effort costs and perceived availability of resources. This is controlled by interconnections between the rostral prefrontal cortex, dorsolateral prefrontal cortex, orbitofrontal cortex, anterior cingulate cortex and anterior insula cortex (Aston-Jones et al., 2000; Craig, 2002).

In order to present the rationale for the model, firstly, the catecholamines hypothesis is outlined, particularly the mechanisms involved. This is followed by discussion of the weaknesses of the hypothesis, particularly with respect to effects of severe exercise. In section 3 , an interoception model is introduced, followed, in section 4 , by an overview of the model and suggestions for methods to test it.

\section{Catecholamines hypothesis for an acute exercise-cognition interaction}

The development of the catecholamines hypothesis from Cooper's (1973) original study until recently, has been covered previously (McMorris, 2016b; McMorris et al., 2016), therefore in this section, an outline of the hypothesis, as it currently stands, will be presented. Catecholamines act as neuromodulators in the brain regions responsible for cognition, motor control, emotion and perception (Gnegy, 2012). Dopamine is synthesized and released from the ventral tegmental area. Projections from the ventral tegmental area form the mesocorticolimbic pathway, which serves the frontal cortex, insula cortex and the nucleus accumbens in the basal ganglia. Dopamine is also synthesized and released from the substantia nigra pars compacta and forms the nigrostriatal pathway, which projects to the caudate nucleus and putamen of the corpus striatum, which is also part of the basal ganglia (Hosp et al., 2019). Norepinephrine neurons are mainly found in the locus coeruleus and lateral tegmental field. Cell bodies in the locus coeruleus serve the dorsal bundle of the noradrenergic system and have axons ending in the spinal cord, cerebellum, entire cerebral cortex and hippocampus. Neurons in the lateral tegmental field are part of the ventral bundle and serve the brainstem and hypothalamus (Baker et al., 1989; Samuels and Szabadi, 2008). The epinephrine cell bodies, which are found in the pons and medulla, also serve the brainstem and hypothalamus (Halliday et al., 1988).

During low levels of arousal, as during rest or very light exercise, release of dopamine and norepinephrine is slow and tonic. Animal studies have shown that when tonic release is slow, phasic release is attenuated (Grace and Bunney, 1983). Slow tonic release is indicative of low arousal and poor attention/vigilance, while phasic release is necessary for activation by salient and novel stimuli (Rajkowski et al., 1994). Thus, cognitive performance is weak. During moderate intensity exercise, feedback from the afferent interoceptive system and somatosensory cortex project to the ventral medial nucleus of the thalamus, which contains concentrations of A1 and A2 noradrenergic cells that connect directly and indirectly, via the hypothalamus, to the locus coeruleus. This results in elevated tonic release rates, which increases extracellular and extrasynaptic norepinephrine concentrations (Holloway et al., 2013; Rinaman, 2011). Moderate tonic release facilitates phasic release when salient or novel stimuli are presented (Belujon and Grace, 2015). Moreover, norepinephrine tonic stimulation of postsynaptic $\alpha_{1}$-adrenoceptors, released from the locus coeruleus, potentiates the firing of dopamine neurons in the ventral tegmental area (Grenhoff et al., 1993).

In the prefrontal cortex, animal studies have shown that during moderate stress, such as moderate intensity exercise, working memory tasks are facilitated by increased activation of the high affinity $\alpha_{2 \mathrm{~A}^{-}}$ adrenoreceptors and dopaminergic $\mathrm{D}_{1}$-receptors. The high affinity $D_{1}$-receptors are coupled to $G_{s}$ and $G_{\text {olf }}$ guanosine triphosphate (GTP)binding proteins and stimulate cyclic adenosine monophosphate (cAMP) activation, which amplifies the effects of neuronal activity and dampens neural 'noise' by increasing $\gamma$-aminobutyric acid (GABA) interneuron release, which inhibits firing to non-preferred stimuli (Arnsten, 2009, 2011; Gorelova et al., 2002). Similarly, when norepinephrine concentrations are moderate, the high affinity $\alpha_{2 \mathrm{~A}}$-adrenoceptors are activated. These are coupled to $G_{i} / G_{o}$ proteins, activation of which inhibits adenyl 
cyclase activity and closes hyperpolarization-activated cyclic nucleotide-gated channels, which increases the strength of neural signaling in the preferred direction, i.e. enhances the strength of the signal (Wang et al., 2007). Hence $D_{1}$-receptors and $\alpha_{2 A}$-adrenoceptors working together strengthen the signal to noise ratio.

As exercise intensity increases towards central fatigue, tonic release of locus coeruleus-norepinephrine increases and becomes faster, which attenuates phasic firing (Aston-Jones et al., 2000). The extent to which phasic firing is attenuated depends on the intensity of the tonic release. Observation of the data for the effect of acute exercise on cognition suggests that even during severe exercise, salient stimuli still activate phasic release but less consistently than during moderate intensity exercise. So, performance is diminished but not totally inhibited. Indeed, McMorris et al. (2005b) demonstrated increased variability of responses, as measured by the standard deviation of individual participants' mean reaction times, during maximal intensity exercise compared to that during low intensity and moderate intensity exercise. However, actual mean reaction times did not differ significantly between conditions. This supports the notion that high levels of tonic release will induce more interference of phasic release but not eliminate it. Moreover, high extracellular concentrations of norepinephrine activate the lower affinity $\alpha_{1}$-and $\beta$-adrenoceptors in the prefrontal cortex. $\alpha_{1}$-adrenoceptors are coupled to $\mathrm{Gq} / \mathrm{G}_{11}$ proteins, which activate phospholipase $\mathrm{C}$, causing increased $\mathrm{Ca}^{+}$release. which inhibits intracellular signaling, thus dampening neuronal activity. $\beta$-adrenoceptors are coupled with $\mathrm{G}_{S}$ proteins, which increase cAMP activity also resulting in the activation of protein kinase A and the dampening of neuronal activity. Similarly, increased tonic release of dopamine dampens neuronal activity due to further activation of $\mathrm{D}_{1}$-receptors. This would mean that the efficiency of the prefrontal cortex is greatly diminished (Arnsten, 2009, 2011). However, fast tonic activation is thought to have a positive effect on some forms of cognition, especially learning/LTM tasks (Aston-Jones and Cohen, 2005).

\subsection{Issues with the catecholamines hypothesis}

2.1.1. Does exercise need to be above the catecholamines thresholds before it affects cognition?

Although research shows strong support for moderate intensity exercise facilitating cognitive performance, which is consistent with the catecholamines hypothesis, there is an issue with whether the exercise needs to be above the catecholamines thresholds. Chmura et al. (1994) presented evidence to show that exercise needed to reach the norepinephrine and epinephrine thresholds, the points at which peripheral plasma concentrations of norepinephrine and epinephrine begin an exponential rise (Green et al., 1983), before cognition demonstrated an improvement from rest. McMorris et al. (1999) supported this finding. Since then, others have shown improvements in cognition at the ventilatory threshold (Collardeau et al., 2001; Davranche and McMorris, 2009; Hyodo et al., 2012), the point at which ventilatory carbon dioxide shows a greater increase than ventilatory oxygen (Beaver et al., 1985). While Kashihara and Nakahara (2005) demonstrated facilitation at the lactate threshold, the point at which blood lactate concentrations show an exponential rise. The thresholds are highly related to one another (Dean et al., 2003; Mazzeo and Marshall, 1989; Schneider et al., 2000; Yamamoto et al., 1992). Overall, it would appear that the thresholds are valid biomarkers for improved cognition. Sub-threshold, there may be small positive effects probably due to interaction between catecholamines effects and motivation, a process explained in the interoception model.

It should also be noted that intensity is not the only factor with regard to exercise effects on locus coeruleus-norepinephrine release. Hodgetts et al. (1991) found that even an exercise intensity as low as $30 \% \mathrm{VO}_{2 \mathrm{MAX}}$ would demonstrate an exponential increase in plasma norepinephrine and epinephrine if the duration was $>30$ mins. So, it is essential to note that in this article, moderate intensity exercise means moderate intensity of short to moderate duration (10-20 mins).

\subsubsection{Moderate intensity exercise, and tonic and phasic norepinephrine release effects on cognition}

There is limited direct evidence to show the effects of the interaction between tonic and phasic release of catecholamines during and following moderate intensity exercise. McGowan et al. (2019), found that cognition was facilitated following moderate intensity, aerobic exercise but did not induce increased tonic or phasic release of locus coeruleus-norepinephrine, as measured by pupillometry. Mather et al. (2020), using functional magnetic resonance imaging (fMRI) and pupillometry, demonstrated stronger locus coeruleus connectivity with a frontoparietal attentional network that activates selective attention and increased phasic locus coeruleus-norepinephrine release following moderate intensity exercise. However, it is very difficult to determine the intensity of the exercise task used by these authors. Non-exercise studies, using pupillometry, have shown increased tonic and phasic firing of norepinephrine in humans during cognitive tasks and that phasic activity is related to attention to salient stimuli (Gilzenrat et al., 2010; Murphy et al., 2011, 2014; Reimer et al., 2016; Tharp et al., 2015). Overall, however, the evidence that acute exercise induces improved cognition via increased phasic and tonic release of locus coeruleus-norepinephrine is far from proven. Much more research is required.

Interestingly, McGowan et al. (2019) found a statistically significant effect of exercise on P3 amplitude, which has been shown to be to be indicative of locus coeruleus-norepinephrine phasic release in nonexercise studies (Murphy et al., 2014; Sutton et al., 1965). Furthermore, in a review of studies that used electroencephalographic (EEG) measures, Kao et al. (2019), in a meta-analysis, provided evidence for facilitation of cognition following moderate intensity exercise compared to performance at rest and that this was accompanied by increases in P3 amplitude. However, findings were not unequivocal. Moreover, no measures of norepinephrine were taken. Results when measuring P3 amplitude during exercise were less clear, which the authors put down to "heterogeneity in study methodology" (p. 32). Only two similar studies have been undertaken since Kao et al.'s (2019) review. Both failed to provide support for increased phasic release during moderate intensity exercise (Du Rietz et al., 2019; Vonk et al., 2019).

Although the evidence presented above is not very strong for arguing that P3 amplitude is indicative of phasic locus coeruleus-norepinephrine release, Mochizuki et al. (1998) demonstrated a relationship between P3 amplitude during an oddball task and cerebral spinal fluid concentrations of the norepinephrine metabolite methoxyhydroxyphenylglycol (MHPG) in humans. Moreover, during cognitive tasks in non-exercise studies, administration of the norepinephrine antagonist clonidine reduced P3 amplitude (Duncan and Kaye, 1987; Halliday et al., 1994). Nevertheless, much more research is required before P3 amplitude can be confidently used as a biomarker for acute exercise-induced locus coeruleus release of norepinephrine.

\subsubsection{Severe exercise}

The empirical data for an acute exercise effect on cognition during or following severe exercise fails to support the catecholamines hypothesis. One reason may be that there is an element of arbitrariness in choosing $80 \% \mathrm{VO}_{2 \mathrm{MAX}}$ as the lower intensity for classifying exercise as being severe. It was chosen because at this intensity, most individuals will have exceeded the respiratory compensation point (Bergstrom et al., 2013), the point at which partial pressure of arterial carbon dioxide begins to decline (Meyer et al., 2004). Moreover, Bergstrom et al. found no statistically significant difference between the percentage of peak volume of oxygen uptake that elicited the respiratory compensation point and critical power, the point at which the individual cannot maintain homeostasis between the required power output, and the biochemical and physiological responses necessary to maintain exercise performance. At this point, the biochemical and physiological factors change 
continuously with time until fatigue (Jones and Vanhatalo, 2017). Maintaining homeostasis is a key factor in interoception theory and the failure to maintain it is seen as being disruptive to cognition, motivation and emotion, which interact with one another (Craig, 2002). The only study to have measured the effect of exercise on cognition at the respiratory compensation point (Ligeza et al., 2018) showed a deterioration in performance on a modified flanker task following exercise above the respiratory compensation point compared to performance following exercise between the ventilatory threshold and the respiratory compensation point. Logically then, one would expect exercise above the respiratory compensation point to inhibit cognition.

Unfortunately, the lack of studies measuring the respiratory compensation point make even the use of exercise $>80 \% \mathrm{VO}_{2 \mathrm{MAX}}$ as a measure of severe exercise somewhat dubious. Without actually testing for the respiratory compensation point, we cannot be sure that individuals are exercising at a severe level. However, when exercising to central fatigue, as in $\mathrm{VO}_{2 \mathrm{MAX}}$ tests and equivalents, we can be sure that the individual has passed the respiratory compensation point (Jones and Vanhatalo, 2017). However, when we examine cognition during or following exercise at $100 \% \mathrm{VO}_{2 \mathrm{MAX}}, 100 \%$ maximum power output or voluntary exhaustion, which by definition are indicative of central fatigue (Davis and Bailey, 1996), we see that results are still somewhat equivocal (see Table 1). Given that inverted-U effect theory would predict no difference between at rest and during or following maximal intensity exercise, we need to compare differences between cognition during or following moderate intensity exercise compared to maximal intensity. Inverted-U theory would suggest a deterioration at the higher intensity. When, however, we do thjs (see Table 2), we also demonstrate equivocality. Therefore, we need to re-assess what is happening at these high levels of exercise.

One of the factors that has been put forward to attempt to explain the equivocal effect of severe exercise on cognition has been task type (McMorris, 2016b; McMorris et al., 2016). Tasks such as perceptual, e.g. simple and choice reaction time, coincidence anticipation timing; shortterm memory or recall tasks; and autonomic tasks have been seen as being simple and thus, consistent with Yerkes and Dodson's (1908) theory, able to be performed optimally during or after severe exercise (Dietrich, 2009; McMorris et al., 2016). Observation of Tables 1 and 2 does not unequivocally support this. The soccer decision-making tasks shown in Tables 1 and 2 do demonstrate unequivocal support for speed of response being facilitated linearly from rest to maximal intensity exercise but not for accuracy. McMorris et al. (2009) claimed that these tests exact autonomic responses from soccer players, who were the participants in all of the tests except one (McMorris and Graydon, 1996a). In that test, soccer players demonstrated a linear improvement from rest to maximum intensity exercise but non-soccer players did not. However, care should be taken with this claim, as no neuroscientific proof of automaticity has been undertaken and all of the tests are from our laboratory, although Fontana et al. (2009) found similar results. Such findings would be consistent with the results of authors examining non-exercise stressors and implicitly-learned tasks (Masters et al., 2008). Furthermore, they are as hypothesized by Drive Theory (Hull, 1943). On the other hand, executive functions, which are seen as being complex, requiring activation of large areas of the prefrontal cortex and phasic release of dopamine and norepinephrine, are expected to demonstrate a negative effect of severe exercise (Audiffren, 2016; McMorris, 2016b). However, some authors have argued that high levels of tonic release of norepinephrine will aid executive functions that require searching for alternative goals (Aston-Jones and Cohen, 2005; Bondi et al., 2010; Robbins and Roberts, 2007; Usher et al., 1999).

\subsubsection{Catecholamines, central fatigue, and learning and long-term memory}

According to the catecholamines hypothesis, learning and LTM will be affected in a totally different way to other tasks, in that they will benefit from exercise to central fatigue (McMorris, 2016b; McMorris et al., 2016). Consolidation of declarative or explicit memory appears to
Table 1

Studies that have examined performance of cognitive tasks during or following maximal intensity exercise and voluntary exhaustion compared to performance at rest.

\begin{tabular}{|c|c|c|c|c|c|}
\hline Authors & $\mathrm{N}$ & $\begin{array}{l}\text { Exercise } \\
\text { measure }\end{array}$ & $\begin{array}{l}\text { During } \\
\text { or post- } \\
\text { exercise }\end{array}$ & Test(s) & Results \\
\hline $\begin{array}{c}\text { Bard and } \\
\text { Fleury } \\
\text { (1978) }\end{array}$ & 16 & $\begin{array}{l}\text { Voluntary } \\
\text { exhaustion }\end{array}$ & Post & $\begin{array}{l}\text { VS } \\
\text { CA }\end{array}$ & $\begin{array}{l}\text { RT NS } \\
\text { Accuracy } \\
\text { NS }\end{array}$ \\
\hline $\begin{array}{l}\text { Bermejo et al. } \\
\text { (2019) }\end{array}$ & 34 & $\begin{array}{l}\text { Voluntary } \\
\text { exhaustion }\end{array}$ & Post & $\begin{array}{l}\text { DSF } \\
\text { DSB } \\
\text { PVT }\end{array}$ & $\begin{array}{l}\text { Accuracy } \\
\text { facilitation } \\
\text { Accracy NS } \\
\text { RT } \\
\text { inhibition }\end{array}$ \\
\hline $\begin{array}{l}\text { Chmura and } \\
\text { Nazar } \\
\text { (2010) }\end{array}$ & 13 & $\begin{array}{l}100 \% \\
\mathrm{VO}_{2 \mathrm{MAX}}\end{array}$ & Post & CRT & $\begin{array}{l}\text { RT } \\
\text { inhibition }^{a}\end{array}$ \\
\hline $\begin{array}{l}\text { Chmura et al. } \\
\text { (1994) }\end{array}$ & 22 & $\begin{array}{l}100 \% \\
\mathrm{VO}_{2 \mathrm{MAX}}\end{array}$ & During & $\mathrm{CRT}^{\mathrm{b}}$ & RT NS \\
\hline $\begin{array}{l}\text { Coco et al. } \\
\text { (2009) }\end{array}$ & 17 & $\begin{array}{l}\text { Voluntary } \\
\text { exhaustion }\end{array}$ & Post & ACT & $\begin{array}{l}\text { RT } \\
\text { inhibition }\end{array}$ \\
\hline $\begin{array}{l}\text { Di Bernardi } \\
\text { Luft et al. } \\
(2009)\end{array}$ & 30 & $\begin{array}{l}100 \% \\
\mathrm{VO}_{2 \mathrm{MAX}}\end{array}$ & Post & $\begin{array}{l}\text { SRT } \\
\text { CRT } \\
\text { 1-back } \\
\text { STM } \\
\text { CONT MON }\end{array}$ & $\begin{array}{l}\text { RT NS } \\
\text { RT NS } \\
\text { RT } \\
\text { facilitation } \\
\text { Accuracy } \\
\text { NS } \\
\text { RT NS } \\
\text { Accuracy } \\
\text { NS } \\
\text { RT NS } \\
\text { Accuracy } \\
\text { NS }\end{array}$ \\
\hline $\begin{array}{l}\text { Féry et al. } \\
\text { (1997) }\end{array}$ & 13 & $\begin{array}{l}\text { Voluntary } \\
\text { exhaustion }\end{array}$ & During & $\begin{array}{l}\text { Recognition } \\
\text { task }\end{array}$ & $\begin{array}{l}\text { RT } \\
\text { inhibition }\end{array}$ \\
\hline $\begin{array}{l}\text { Finkenzeller } \\
\text { et al. (2018) }\end{array}$ & 12 & $\begin{array}{l}\text { Voluntary } \\
\text { exhaustion }\end{array}$ & Post & Flanker & $\begin{array}{l}\text { RT } \\
\text { facilitation } \\
\text { Accuracy } \\
\text { NS }\end{array}$ \\
\hline $\begin{array}{l}\text { Griffin et al. } \\
\text { (2011) }\end{array}$ & 30 & $\begin{array}{l}100 \% \\
\mathrm{VO}_{2 \mathrm{MAX}}\end{array}$ & Post & $\begin{array}{l}\text { SWCT } \\
\text { Learning/ } \\
\text { memory }\end{array}$ & $\begin{array}{l}\text { Accuracy } \\
\text { NS } \\
\text { RT NS } \\
\text { Accuracy } \\
\text { facilitation }\end{array}$ \\
\hline $\begin{array}{l}\text { Isaacs and } \\
\text { Pohlman } \\
\text { (1991) }\end{array}$ & 12 & $\begin{array}{l}100 \% \\
\mathrm{VO}_{2 \mathrm{MAX}}\end{array}$ & During & CA & $\begin{array}{l}\text { Accuracy } \\
\text { inhibition }\end{array}$ \\
\hline $\begin{array}{c}\text { Kamijo et al. } \\
\text { (2004a) }\end{array}$ & 12 & $\begin{array}{l}\text { Voluntary } \\
\text { exhaustion }\end{array}$ & Post & Go/NoGo & EMG-RT NS \\
\hline $\begin{array}{l}\text { Kamijo et al. } \\
\text { (2004b) }\end{array}$ & 12 & $\begin{array}{l}\text { Voluntary } \\
\text { exhaustion }\end{array}$ & Post & Go/NoGo & EMG-RT NS \\
\hline $\begin{array}{l}\text { McMorris and } \\
\text { Graydon } \\
\text { (1996a) }\end{array}$ & 20 & $\begin{array}{l}100 \% \\
\dot{\mathrm{W}}_{\mathrm{MAX}}\end{array}$ & During & SDM & $\begin{array}{l}\text { Accuracy } \\
\text { NS } \\
\text { RT } \\
\text { facilitation }\end{array}$ \\
\hline $\begin{array}{l}\text { McMorris and } \\
\text { Graydon } \\
\text { (1996b) }\end{array}$ & 10 & $\begin{array}{l}100 \% \\
\dot{W}_{\text {MAX }}\end{array}$ & During & SDM & $\begin{array}{l}\text { Accuracy } \\
\text { NS } \\
\text { RT } \\
\text { facilitation }^{a}\end{array}$ \\
\hline $\begin{array}{l}\text { McMorris and } \\
\text { Graydon } \\
\text { (1996b) }\end{array}$ & 20 & $\begin{array}{l}100 \% \\
\dot{\mathrm{W}}_{\operatorname{MAX}}\end{array}$ & During & SDM & $\begin{array}{l}\text { Accuracy } \\
\text { NS } \\
\text { RT } \\
\text { facilitation }\end{array}$ \\
\hline $\begin{array}{l}\text { McMorris and } \\
\text { Graydon } \\
\text { (1997) }\end{array}$ & 12 & $\begin{array}{l}100 \% \\
\dot{W}_{\text {MAX }}\end{array}$ & During & VS & $\begin{array}{l}\text { RT } \\
\text { facilitation }\end{array}$ \\
\hline $\begin{array}{l}\text { McMorris and } \\
\text { Graydon } \\
\text { (1997) }\end{array}$ & 12 & $\begin{array}{l}100 \% \\
\dot{W}_{\text {MAX }}\end{array}$ & During & SDM & $\begin{array}{l}\text { Accuracy } \\
\text { facilitation } \\
\text { RT } \\
\text { facilitation }\end{array}$ \\
\hline $\begin{array}{l}\text { McMorris and } \\
\text { Keen (1994) }\end{array}$ & 12 & $\begin{array}{l}100 \% \\
\dot{\mathrm{W}}_{\text {MAX }}\end{array}$ & During & SRT & $\begin{array}{l}\text { RT } \\
\text { inhibition }\end{array}$ \\
\hline $\begin{array}{l}\text { McMorris } \\
\text { et al. (1999) }\end{array}$ & 9 & $\begin{array}{l}100 \% \\
\dot{\mathrm{W}}_{\text {MAX }}\end{array}$ & During & SDM & $\begin{array}{l}\text { Accuracy } \\
\text { NS } \\
\text { RT } \\
\text { facilitation } \\
\text { on next page) }\end{array}$ \\
\hline
\end{tabular}


Table 1 (continued)

\begin{tabular}{|c|c|c|c|c|c|}
\hline Authors & $\mathrm{N}$ & $\begin{array}{l}\text { Exercise } \\
\text { measure }\end{array}$ & $\begin{array}{l}\text { During } \\
\text { or post- } \\
\text { exercise }\end{array}$ & Test(s) & Results \\
\hline $\begin{array}{l}\text { McMorris } \\
\text { et al. } \\
\text { (2005a) }\end{array}$ & 12 & $\begin{array}{l}100 \% \\
\dot{\mathrm{W}}_{\text {MAX }}\end{array}$ & During & CRT & $\begin{array}{l}\text { RT } \\
\text { inhibition }\end{array}$ \\
\hline $\begin{array}{l}\text { McMorris } \\
\text { et al. } \\
\text { (2005b) }\end{array}$ & 9 & $\begin{array}{l}100 \% \\
\dot{\mathrm{W}}_{\text {MAX }}\end{array}$ & During & NC-CRT & RT NS \\
\hline $\begin{array}{l}\text { McMorris } \\
\text { et al. (2009) }\end{array}$ & 24 & $100 \%$ MAP & During & Flanker task & $\begin{array}{l}\text { Accuracy } \\
\text { inhibition } \\
\text { RT } \\
\text { inhibition }\end{array}$ \\
\hline $\begin{array}{l}\text { Sjöberg } \\
\text { (1980) }\end{array}$ & 48 & $\begin{array}{l}100 \% \\
\dot{\mathrm{W}}_{\text {MAX }}\end{array}$ & $\begin{array}{l}\text { During } \\
\text { and } \\
\text { Post }\end{array}$ & STM & $\begin{array}{l}\text { Accuracy } \\
\text { NS during } \\
\text { and post }\end{array}$ \\
\hline $\begin{array}{l}\text { Sudo et al. } \\
\text { (2017) }\end{array}$ & 18 & $\begin{array}{l}\text { Voluntary } \\
\text { exhaustion }\end{array}$ & Post & $\begin{array}{l}\text { Spatial DR } \\
\text { Go/No Go }\end{array}$ & $\begin{array}{l}\text { Accuracy } \\
\text { NS } \\
\text { RT NS } \\
\text { Accuracy } \\
\text { NS }\end{array}$ \\
\hline $\begin{array}{l}\text { Thomson et al. } \\
\text { (2009) }\end{array}$ & 163 & $\begin{array}{l}100 \% \\
\mathrm{VO}_{2 \mathrm{MAX}}\end{array}$ & Post & $\begin{array}{l}\text { Speed } \\
\text { discrimination }\end{array}$ & $\begin{array}{l}\text { RT NS } \\
\text { Accuracy } \\
\text { inhibition }\end{array}$ \\
\hline $\begin{array}{l}\text { Tomporowski } \\
\text { et al. (1987) }\end{array}$ & 24 & $\begin{array}{l}\text { Voluntary } \\
\text { exhaustion }\end{array}$ & Post & STM & $\begin{array}{l}\text { Accuracy } \\
\text { NS }\end{array}$ \\
\hline
\end{tabular}

ACT; attention and concentration task; CA coincidence anticipation; CONT MON continuous monitoring; CRT choice reaction time; DR delayed response; DSB digit span backwards; DSF digit span forward; EMG electromyography; MAP maximum aerobic power; NC-CRT non-compatible reaction time; NS nonsignificant; PVT perceptual vigilance task; RT reaction time; SDM soccer decision-making test; STM short-term memory; SRT simple reaction time; SWCT Stroop worid color test; $\mathrm{T}_{\mathrm{Epi}}$ epinephrine threshold; $\mathrm{T}_{\mathrm{NE}}$ norepinephrine threshold; $\mathrm{VO}_{2 \mathrm{MAX}}$ maximum volume of oxygen uptake; VS visual search; $\dot{\mathrm{W}}_{\mathrm{MAX}}$ maximum power output.

be primarily undertaken by the hippocampus and requires the process of long-term potentiation (LTP), the strengthening of synaptic connections between neurons (Bliss and Lømo, 1973). Processes of consolidation in implicit memory are less well understood. Although there are some common brain activations during explicit and implicit learning, distinct neural mechanisms serve explicit versus implicit learning/memory
(Yang and Li, 2012).

The early stages of learning and LTP consolidation, known as earlyLTP, which lasts for about 4-6 h (Straube et al., 2003), do not involve catecholamines. During heavy exercise, nitric oxide is released from the endothelium (Tanaka et al., 2015). Nitric oxide signaling is mostly mediated by soluble guanylyl cyclase (Arnold et al., 1977) and this leads to the activation of cyclic guanosine monophosphate-dependent protein kinase (PKG). PKG, in turn, enhances neurotransmitter release (Hawkins et al., 1993, 1998) and this forms the basis of early-LTP. However, norepinephrine is vital for late LTP, which has a duration of $>4-6 \mathrm{~h}$ (Hu et al., 2007; Yang and Li, 2012). Exercise to central fatigue induces high concentrations of norepinephrine in the hippocampus, where it activates $\beta$-adrenoceptors, but it also results in increases in serum and plasma concentrations of the protein, brain derived neurotrophic factor (BDNF), in humans (Ferris et al., 2007; Rasmussen et al., 2009). In explicit memory, norepinephrine stimulates cAMP activation, which modulates the signaling and trafficking of the BDNF receptor tropomyosin-related kinase B (Trk B: Ji et al., 2005; Yamada and Nabeshima, 2003). The binding of BDNF to Trk B initiates a number of intracellular signaling cascades, resulting in the phosphorylation of cAMP-response element binding protein (CREB: Binder and Scharfman, 2004). The whole process modulates synaptic transmission in a lasting manner by modifying synaptic protein composition via local protein synthesis (Waterhouse and $\mathrm{Xu}, 2009$ ).

LTP also occurs during implicit learning (Bailey et al., 2015; Horvitz, 2009), but there are some differences in the mechanisms. The hippocampus is thought to play a part in the learning of some but, not all, implicit tasks (Albouy et al., 2008), but the basal ganglia, in particular the striatum, are heavily involved in implicit learning (Poldrack et al., 2005; Reber and Squire, 1994). While $\beta$-adrenoceptors are present in the basal ganglia (Reznikoff et al., 1986) and may regulate BDNF/Trk B activity, the dopaminergic system is dominant and high concentrations of dopamine have been shown to aid learning in this region in animals (Wickens et al., 2007). Like $\beta$-adrenoceptors, dopaminergic $D_{1}$-receptors are GTP-binding proteins, with cAMP as the second messenger. Cyclic AMP activates protein kinase $\mathrm{A}$, which, in turn, activates CREB resulting in LTP (Tritsch and Sabatini, 2012).

Whether for explicit or implicit tasks, the relationship between LTP and LTM is controversial. There are some definite similarities but also

Table 2

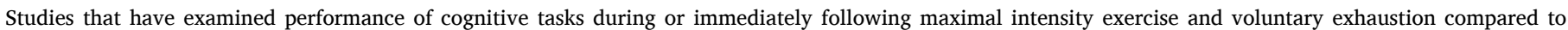
performance during or immediately following moderate intensity exercise.

\begin{tabular}{|c|c|c|c|c|c|c|}
\hline Author(s) & $\mathrm{N}$ & Moderate intensity & Heavy intensity & Task & During or Post-exercise & Results \\
\hline Chmura et al. (1994) & 22 & $\begin{array}{l}\mathrm{T}_{\mathrm{Epi}} \\
\mathrm{T}_{\mathrm{NE}}\end{array}$ & $100 \% \mathrm{VO}_{2 \mathrm{MAX}}$ & CRT & During & RT inhibition \\
\hline Isaacs and Pohlman (1991) & 12 & $75 \% \mathrm{VO}_{2 \mathrm{MAX}}$ & $100 \% \mathrm{VO}_{2 \mathrm{MAX}}$ & $\mathrm{CA}$ & During & Accuracy inhibition \\
\hline Kamijo et al. (2004a) & 12 & RPE 12-14 & Voluntary exhaustion & Go/NoGo & Post & NS \\
\hline Kamijo et al. (2004b) & 12 & RPE 12-14 & Voluntary exhaustion & Go/NoGo & Post & NS \\
\hline McMorris and Graydon (1996a) & 20 & $70 \% \dot{\mathrm{W}}_{\mathrm{MAX}}$ & $100 \% \dot{\mathrm{W}}_{\mathrm{MAX}}$ & SDM & During & $\begin{array}{l}\text { Accuracy NS } \\
\text { RT facilitation }\end{array}$ \\
\hline McMorris and Graydon (1996b) & 10 & $70 \% \dot{\mathrm{W}}_{\mathrm{MAX}}$ & $100 \% \dot{\mathrm{W}}_{\mathrm{MAX}}$ & SDM & During & $\begin{array}{l}\text { Accuracy NS } \\
\text { RT facilitation }\end{array}$ \\
\hline McMorris and Graydon (1996b) & 20 & $70 \% \dot{\mathrm{W}}_{\mathrm{MAX}}$ & $100 \% \dot{\mathrm{W}}_{\mathrm{MAX}}$ & SDM & During & $\begin{array}{l}\text { Accuracy NS } \\
\text { RT facilitation }\end{array}$ \\
\hline McMorris and Graydon (1997) & 12 & $70 \% \dot{\mathrm{W}}_{\mathrm{MAX}}$ & $100 \% \dot{\mathrm{W}}_{\mathrm{MAX}}$ & VS & During & RT facilitation \\
\hline McMorris and Graydon (1997) & 12 & $70 \% \dot{\mathrm{W}}_{\mathrm{MAX}}$ & $100 \% \dot{\mathrm{W}}_{\mathrm{MAX}}$ & SDM & During & $\begin{array}{l}\text { Accuracy facilitation } \\
\text { RT facilitation }\end{array}$ \\
\hline McMorris and Keen (1994) & 12 & $70 \% \dot{\mathrm{W}}_{\mathrm{MAX}}$ & $100 \% \dot{\mathrm{W}}_{\mathrm{MAX}}$ & $\mathrm{SRT}^{b}$ & During & RT inhibition \\
\hline McMorris et al. (1999) & 9 & $\mathrm{~T}_{\mathrm{Epi}}$ & $100 \% \dot{\mathrm{W}}_{\text {MAX }}$ & SDM & During & $\begin{array}{l}\text { RT NS } \\
\text { Accuracy NS }\end{array}$ \\
\hline McMorris et al. (2005a) & 12 & $70 \% \dot{W}_{\text {MAX }}$ & $100 \% \dot{\mathrm{W}}_{\mathrm{MAX}}$ & CRT & During & RT inhibition \\
\hline McMorris et al. (2005b) & 9 & $70 \% \dot{W}_{\text {MAX }}$ & $100 \% \dot{W}_{\text {MAX }}$ & NC-CRT & During & RT NS \\
\hline McMorris et al. (2009) & 24 & $50 \%$ MAP & $100 \%$ MAP & Flanker task & During & $\begin{array}{l}\text { RT inhibition } \\
\text { Accuracy inhibition }\end{array}$ \\
\hline
\end{tabular}

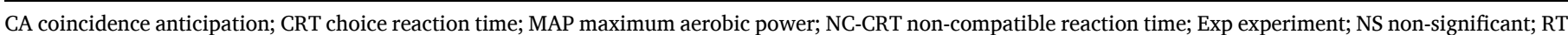

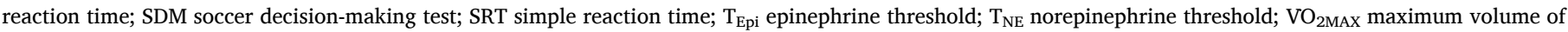
oxygen uptake; VS visual search; $\dot{\mathrm{W}}_{\mathrm{MAX}}$ maximum power output. 
differences (Tonegawa et al., 2015). It is not within the scope of this article to discuss these issues but it is important to point out that there are differences between LTP and LTM. We have seen the role of norepinephrine and dopamine in LTP formation and several authors claim that catecholamines, in particular norepinephrine, also play roles as modulators in the formation of memory engrams, which constitute LTM (Alberini et al., 2017; Suzuki and Bozdagi, 2011).

Two studies (Griffin et al., 2011; Winter et al., 2007) have examined the effects of severe exercise on LTM/learning. In both studies facilitation was demonstrated. Winter et al., 2007 demonstrated high plasma concentrations of norepinephrine and epinephrine, and high serum concentrations of BDNF during consolidation. Although Griffin et al. did not measure catecholamines concentrations, they showed high serum concentrations of BDNF following severe exercise. Both studies utilized explicit memory and undertook the exercise in the LTM consolidation phase. This appears to be the best time to undertake the exercise as it is the period that requires LTP, which is dependent on increased concentrations of BDNF and norepinephrine. Exercising during the acquisition phase would probably also be beneficial in that increased arousal would facilitate attention and hence the quality of understanding what is to be learned, which is thought to aid learning (Craik and Lockhart, 1972). Far more research is needed to examine the timing of acute exercise as an aid to learning/LTM.

\subsubsection{Catecholamines, cognition and long duration, moderate intensity exercise}

None of the studies examined above utilized long duration, moderate intensity exercise, although according to the catecholamines hypothesis, this intensity $x$ duration should have similar negative effects to those hypothesized for severe exercise. Grego et al. (2004) demonstrated an inverted-U effect on an auditory oddball task and P3 amplitude during 3 hours of low to moderate intensity exercise. Only one other study has been undertaken (Peyrin et al., 1987). These authors compared urinary concentrations of norepinephrine, epinephrine, dopamine, an adrenaline metabolite, metanephrine; and the metabolites of norepinephrine normetanephrine, and sulfate, glucuronide and total MHPG following cognitive performance at rest and after cycling for 1 hour at $\sim 75 \%$ $\mathrm{VO}_{\text {MAXX }}$. Participants showed improved performance during exercise on one dependent variable for a word discrimination test but not on another nor on an arithmetic calculation task. There were increased urinary concentrations of epinephrine, norepinephrine and MHPG sulfate. Moreover, linear regression analyses found significant correlations between performance on the word discrimination test, on which participants showed improved performance during exercise, and $\Delta$ epinephrine plus $\Delta$ metanephrine $(r=0.61)$, and $\Delta$ MHPG sulfate $(r=$ 0.63 ) concentrations. That performance improved following one hour of exercise is consistent with the findings of Grego et al. (2004, 2005).

\section{Toward an interoception model for the acute exercise- cognition interaction}

In the previous section, we saw how the catecholamines hypothesis can provide a rationale for the results of research into the effects of moderate intensity exercise on cognition, but not for the results of studies in which participants exercised maximally. The mechanisms that result in increased extracellular concentrations of catecholamines during exercise are part of the interoception system and their activation has been claimed to be involved in the phenomenon of central fatigue (Hilty et al., 2011; McMorris et al., 2018a; Robertson and Marino, 2016). Modern interpretations of interoception, however, are not merely mechanistic but involve interpretation and integration of cognitive, perceptive, motor and emotional information (Craig, 2002; Critchley and Garfinkel, 2017; Damasio, 1994). In this section, therefore, a rationale for an interoception model for the acute exercise-cognition interaction effect is presented. The factors that need to be taken into consideration when attempting to account for the acute exercise- cognition interaction are complex and multi-faceted. Critchley and Garfinkel pointed this out for the psychological stress-behavior effects. This should not be surprising, given the current knowledge concerning behavioral and cognitive neuroscience, and neural connectivity during complex cognitive, emotional and physical activities (Pessoa et al., 2019). While the underlying interoceptive processes described below are common to all types of stressor and behavior, the psychological factors are more specific to acute exercise, although even here there is overlap with other stressors.

\subsection{Mechanisms of the interoceptive system during exercise}

The decision to undertake physical exercise may be stimulated by internal or external input. Human studies (Asahara et al., 2016; Ishii et al., 2018; Matsukawa et al., 2015) have demonstrated activation of the dorsolateral and ventrolateral prefrontal cortices prior to commencement of exercise. Human research in non-exercise situations shows that decisions to undertake actions that are externally stimulated, require activation of the dorsolateral prefrontal cortex. However, when the decision is internally driven, the rostral prefrontal cortex, also known as the frontopolar cortex and anterior prefrontal cortex, is also activated (see Christoff and Gabrieli, 2000, for a review). It is thought that the rostral prefrontal cortex feeds forward to the lateral prefrontal cortex, which triggers activation of the cerebral-basal ganglia-thalamocerebellar pathway, which controls motor activity (Doya, 2000; Shadmehr, 2008). The dorsolateral prefrontal cortex also feeds forwards, in the form of corollary discharge, to the anterior insula cortex, concerning the predicted feedback from lamina 1 lateral spinothalamocortical, and vagal and glossopharyngeal afferents, concerning the interoceptive state of the individual (Christensen et al., 2007; Craig, 2002; Gu et al., 2013; Lovero et al., 2009).

\subsubsection{Afferent interoceptive mechanisms}

Human studies have shown that during exercise, small-diameter A\&and C-type primary afferent fibers, which sense the physiological condition of all tissues of the body and terminate in lamina 1 of the spinal and trigeminal dorsal horns, relay afferent information from the lateral spinothalamic tract to the main homeostatic integration sites in the brainstem, which also receive vagal and glossopharyngeal afferent feedback via the nucleus of the solitary tract (Kitahama et al., 1985; Saper et al., 1991; Sharma et al., 2010). The lamina 1 lateral spinothalamic and nucleus of the solitary tract medullothalamic axons terminate in the posterior and basal parts of the ventral medial nucleus of the thalamus (Halliday et al., 1988; Saper et al., 1991), which project to the insula cortex (Critchley and Harrison, 2013; Hilty et al., 2011). The anterior insula cortex also receives proprioceptive afferent input from large diameter sensory fibers in skin, muscles and joints via the somatosensory cortex (Martin et al., 2008).

According to Craig's $(2002,2015)$ interoception theory, in order to generate a current awareness state, the anterior insula cortex constantly compares bottom-up interoceptive feedback with the top-down predictions of interoceptive state, which it received from the dorsolateral prefrontal cortex pre-task, in this case pre-exercise. Blakemore et al. (1998), using positron emission tomography (PET), demonstrated this in humans. Based on animal research, Craig (2002) argued that this information is forwarded to the anterior cingulate cortex. In humans, high angular resolution diffusion imaging has shown that the anterior insula cortex and anterior cingulate cortex are structurally connected and demonstrate coactivation (Ghaziri et al., 2017). With specific regard to human exercise, Weng et al. (2017), in a fMRI study, demonstrated exercise-induced increased functional connectivity between the ventromedial prefrontal cortex (including the orbitofrontal cortex) and the right anterior insula cortex. This has been further supported by Williamson and colleagues (Williamson et al., 1997; Williamson et al., 1999, 2001, 2002), and Critchley et al. (2000). Human studies also show that the anterior insula cortex and anterior cingulate cortex have 
bidirectional projections with the ventromedial prefrontal cortex, which also has connections with the lateral prefrontal cortex, amygdala, striatum, and thalamus (Alexander et al., 1986; Ghaziri et al., 2017; Holroyd, 2002; Weng et al., 2017). In the following sub-sections, the ways in which this information affects cognition are discussed.

\subsection{How interoception influences the acute exercise-catecholamines- cognition interaction}

\subsubsection{Moderate intensity exercise}

During moderate intensity exercise, interoceptive feedback from the lamina 1 afferents, and vagal and glossopharyngeal nerves activate A1, A2 and locus coeruleus (A6) noradrenergic neurons in the brainstem, thus stimulating increased tonic release of norepinephrine from the locus coeruleus. This increases arousal and facilitates phasic release of norepinephrine from the locus coeruleus, and dopamine from the ventral tegmental area and substantia nigra pars compacta (Floresco et al., 2003; Grace, 1991). Activation of $\mathrm{D}_{1}$ dopaminergic receptors and $\alpha_{2 \mathrm{~A}}$-adrenoceptors is also stimulated, which strengthen the signal to noise ratio. Hence cognitive performance is facilitated. This is consistent with the catecholamines hypothesis. However, although the empirical results demonstrate a positive effect of moderate intensity exercise on cognition, this is not unequivocal. In some studies, where the at rest cognitive test immediately precedes the undertaking of the exercise protocol, feedforward from the lateral prefrontal cortex to the hypothalamus can trigger tonic release of dopamine from the ventral tegmental area and substantia nigra pars compacta, and norepinephrine from the locus coeruleus in anticipation of undertaking the exercise (Mason et al., 1973; McMorris et al., 2008; McMorris et al., 2009). This increase in tonic release may be sufficient to facilitate activation of phasic release in the presence of salient stimuli. This could result in performance at rest being as good as that during moderate intensity exercise, as demonstrated by McMorris et al. (2009) for a random number generation task.

While the situation described above is not contrary to the catecholamines hypothesis, there is another situation in which there may be no difference between performance at rest and during moderate intensity exercise. If the individual is highly motivated, this can trigger increased tonic release of dopamine from the ventral tegmental area (BrombergMartin et al., 2010), which can, in turn, induce release of norepinephrine from the locus coeruleus (Ranjbar-Slamloo and Fazlali, 2020). The increase in tonic release of catecholamines may reach a level which facilitates phasic release in response to the presentation of salient stimuli. Hence cognitive performance would be as good as during moderate intensity exercise. This is consistent with Kahneman's (1973) claim that under low levels of stress, motivated individuals can perform as well as they do during moderate levels, if they allocate resources to the task. Unfortunately, while studies that measure catecholamines concentrations can explain the effects of increased concentrations due to anticipation of the exercise, I was not able to find any studies that have measured motivation levels. Therefore, when there is no difference between cognition at rest and during moderate exercise, we do not know the cause. It could simply be statistical, i.e. low power, but it could also be explained by the process outlined above, which is consistent with Craig's (2002) interoception theory.

\subsubsection{Severe exercise}

In this sub-section, I present the case for the effects of severe exercise, i.e., exercise above the respiratory compensation point (Bergstrom et al., 2013), on cognition. I do, however, acknowledge that the supporting empirical data are from maximal intensity exercise studies apart from that of Ligeza et al. (2018), but interoception theory (Craig, 2002, 2006) would strongly suggest that during severe exercise, including exercise to central fatigue, the interaction between interoceptive feedback, catecholamines, homeostasis, motivation and emotions will all contribute to the effects of exercise on cognition.
The catecholamines hypothesis provides a strong rationale for positive effects of severe, acute exercise on learning and LTM. Although the empirical evidence is limited, what there is supports a facilitative effect (Griffin et al., 2011; Winter et al., 2007). However, the main concern for this article is to account for the failure of the catecholamines hypothesis to predict the empirical results for perceptual, short-term memory and executive function tasks, and to provide an alternative model. Therefore, in this sub-section, the case for interoception providing a viable explanation for the empirical data is presented.

Exercising at $100 \% \mathrm{VO}_{2 \mathrm{MAX}}, 100 \%$ maximum power output or until voluntary exhaustion means that the person has reached central fatigue. Research into central fatigue shows that humans actually stop exercising before their physical limits are reached (Gandevia, 2001; Newsholme et al., 1987). Based on Craig's (2002) interoception theory, proponents of theories of central fatigue (Hilty et al., 2011; McMorris et al., 2018a; Robertson and Marino, 2016). have pointed to research showing that comparison of interoceptive feedback held in the orbitofrontal cortex and anterior cingulate cortex is thought to evaluate choice options and encode outcome expectations (Schoenbaum et al., 2009). We (McMorris, 2020; McMorris et al., 2018a) argued that this information is projected to the lateral prefrontal cortex, which integrates the information received from these regions, as well as information received from the anterior insula cortex and somatosensory cortex, and a decision concerning what action to take is made (Cole et al., 2013; Nee and D'Esposito, 2016), although a role for the rostral prefrontal cortex is also claimed by some authors (Koechlin and Hyafil, 2007). It may be that this brain region sets the parameters to be used by the lateral prefrontal, orbitofrontal and anterior cingulate cortices in the evaluation of choice options. This is consistent with Burgess and Wu's (2013) conclusion that the overall function of the rostral prefrontal cortex is as a "hub for metacognition" (their italics: p. 524). In this article, I propose that something similar happens with regard to the effect of severe exercise on cognition.

When the cognitive task is being administered following the end of exercise, the individual will have reached the point of central fatigue and induced increased tonic locus coeruleus-norepinephrine release. Human studies, examining cognition following severe exercise, using EEG measurements of P3 amplitude, demonstrated less phasic release and greater tonic release at cessation of the exercise and a deterioration in performance in the subsequent cognitive task (Kamijo et al., 2004a, 2004b; Kao et al., 2017). This is consistent with Aston-Jones and Cohen's (2005) Adaptive Gain Theory and Craig's (2002) interoception theory, as fast tonic release would attenuate phasic release and hence inhibit responses to salient bottom-up and top-down stimuli. Moreover, the increased extracellular catecholamines concentrations would result in greater activation of $D_{1}$-receptors, $\alpha_{1}$-and $\beta$-adrenoceptors, which would dampen all cognitive activity (Arnsten, 2009). This will occur if the person perceives the effort required as being beyond the resources available and/or not worth the effort as the reward is poor (Craig, 2002, 2015). However, tonic release favors performance of tasks which call for a switch to dealing with different stimuli-response requirements or alternative courses of action (Aston-Jones and Cohen, 2005). Thus, such tasks may show facilitation of performance during severe exercise.

However, if the person decides that by stopping exercising and focusing on cognition only, they will have sufficient resources for the task, the situation will be different. This judgment will depend on comparison of sensory predictions received by the anterior insula cortex from the lateral prefrontal cortex pre-exercise and the actual feedback. The accuracy of the prediction is dependent on psychological factors, which affect interoception. Adaptive Gain Theory (Aston-Jones and Cohen, 2005) postulates that in such cases, the orbitofrontal and anterior cingulate cortices project to the locus coeruleus by electrical coupling, which lowers tonic release rate thus enhancing phasic release (Usher et al., 1999). Moreover, Aston-Jones et al. (2004) found that GABAergic neurons in the peri-locus coeruleus innervate locus coeruleus-norepinephrine neurons which would attenuate tonic 
norepinephrine release. Thus, performance may be maintained at the same level as that during moderate intensity exercise. If, however, the perception of effort costs and/or available resources is incorrect, in other words they think that they can meet the demands but actually can not, performance will decrease as they will be unable to induce phasic responses consistently.

The situation, when the cognitive task is being undertaken during the exercise rather than following the exercise, is slightly different. When the cognitive task is undertaken during exercise, one would expect the participant to determine the effort costs and resources required to energize the behavior, based on the accumulative costs of undertaking the exercise plus the cognitive task and not on the demands of the exercise per se. This would include taking into account the dual task nature of the activity. Therefore, one would expect to see phasic locus coeruleus-norepinephrine release and cognitive performance maintained until cessation of the exercise, when increased tonic release will be triggered. This will, however, only be the case when the judgement concerning resources and task requirements is correct. If not, it may result in deterioration of performance due to increased tonic release occurring earlier than expected.

\subsection{Psychological factors}

The psychological factors affecting the ways in which interoception influences the acute exercise-catecholamines-cognition interaction, fall primarily into two areas, motivation and perception of effort. They are similar to those which McMorris et al. (2018a) claimed to be important in perception of central fatigue. However, unlike the central fatigue factors, which are concerned only with the physical effort, these also involve issues relating to cognitive effort. Moreover, they are similar to those of early cognitive psychology theories concerning the effects of stress on performance of a variety of tasks (Kahneman, 1973; Hull, 1943; Humphreys and Revelle, 1984). It is not the purpose of this study to examine these factors in any detail but simply to outline the major influences on interactions between the the brain regions involved in determining the motivational/reward evaluation, the perception of effort required to perform the task and the perception of the available resources. The motivational/reward pathway consists of the dorsolateral prefrontal cortex, orbitofrontal cortex, cingulate cortex, amygdala and basal ganglia (Spielberg et al., 2012; Weng et al., 2017), although the rostral prefrontal cortex has also been implicated (Christoff and Gabrieli, 2000; Soutschek et al., 2018). In 3.2.2, we saw that comparison of interoceptive feedback held in the orbitofrontal cortex and anterior cingulate cortex is responsible for decisions concerning perception of effort. However, this is in fact just the final product of almost all of the interoceptive system, particularly the anterior insula cortex, lateral prefrontal cortex and basal ganglia. Moreover, dopaminergic neurons are thought to be responsible for encoding the expected reward and anticipating the effort cost, while noradrenergic neurons mobilize resources in order to energize the behavior necessary for successful completion of the task (Bouret et al., 2012; Varazzani et al., 2015).

Fig. 1 outlines the major influences that I propose, affect perception of effort costs. Observation of these factors shows that there will obviously be inter-individual differences in responses to the situation, particularly during severe exercise. Moreover, the importance of past experience of similar situations, changes to short- and long-term goals and changing fitness levels means that there will also be intra-individual differences as people gain experience.

\section{Overview and testing of the model}

\subsection{Overview of the interoception model for an acute exercise-cognition interaction}

In this sub-section, I present a brief outline of the proposed model (see Fig. 2). At rest and during low intensity exercise ( $<40 \% \mathrm{VO}_{2 \mathrm{MAX}}$ or

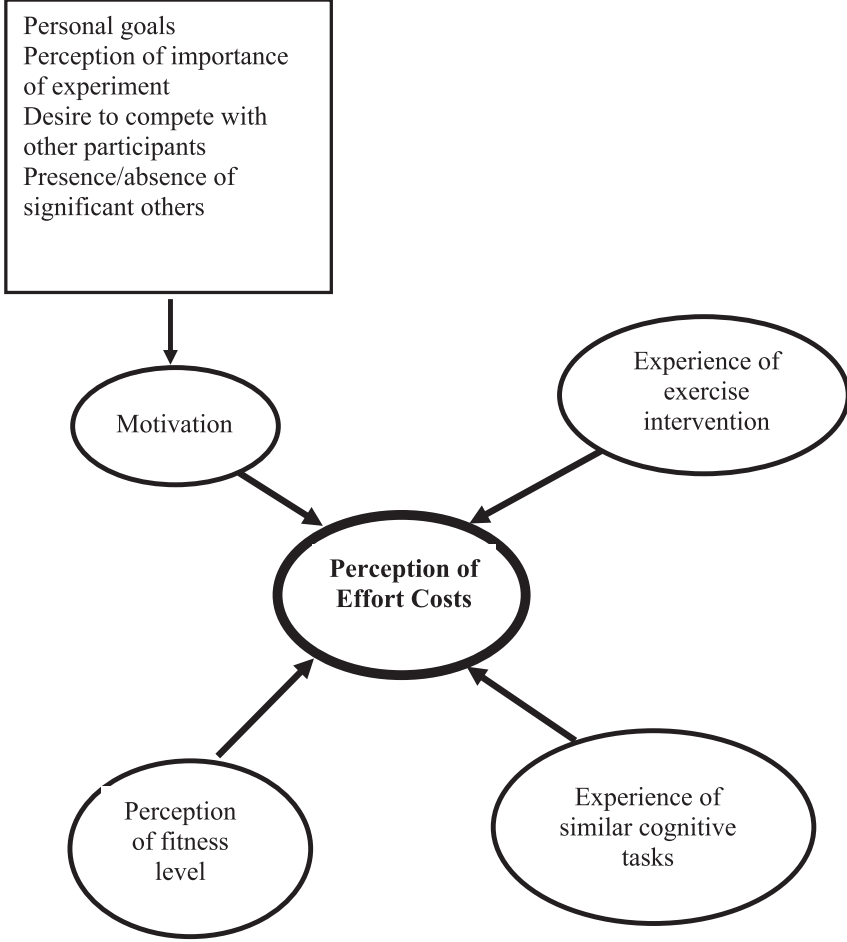

Fig. 1. Psychological factors affecting perception of effort costs.

equivalent), slow tonic release of catecholamines inhibits arousal and attention, which negatively affects all types of cognitive task. It also attenuates phasic release of catecholamines, which negatively affects responses to salient top-down and bottom-up stimuli. However, highly motivated individuals can trigger release of dopamine from the ventral tegmental area, which also induces locus coeruleus-norepinephrine release (Ranjbar-Slamloo and Fazlali, 2020). As a result, cognitive performance may be as good as during moderate intensity exercise. This can also occur if the individual is expected to undertake exercise immediately following the cognitive task, which can induce increased tonic release of catecholamines due to the hypothalamus initiating locus coeruleus-norepinephrine release in anticipation of the upcoming exercise. However, it remains to be seen if even highly motivated individuals can perform equally as well at rest as during moderate intensity exercise. In other words, can motivation trigger a sufficient increase in tonic release of catecholamines to induce increases in extracellular concentrations of catecholamines that are on a par with those released during moderate intensity exercise?

During moderate intensity exercise, especially that following the norepinephrine threshold or equivalents, greater tonic release of norepinephrine from the locus coeruleus results in increased extracellular norepinephrine and, via the ventral tegmental area and substantia nigra pars compacta, larger dopamine concentrations. This results in optimal phasic release of the catecholamines, and activation $\alpha_{2 \mathrm{~A}}$-adrenoceptors and $\mathrm{D}_{1}$ dopaminergic receptors, which work together to increase the signal to noise ratio. As a result, cognitive performance is optimal. During severe exercise, higher extracellular catecholamines concentrations induce increased tonic release of dopamine and norepinephrine, which attenuates phasic release. Moreover, increased activation of $D_{1}$ receptors. and $\alpha_{1}$ - and $\beta$-adrenoceptors reduces the signal to noise ratio. However, the extent to which this results in inhibition of cognition depends on the motivation level of the individual, their perception of their ability to meet the task demands and whether they think the rewards for performing well are worthwhile achieving. This is determined by interoceptive information held in the orbitofrontal cortex, anterior cingulate cortex and anterior insula cortex being projected to the lateral prefrontal cortex for a decision as to what action to take 


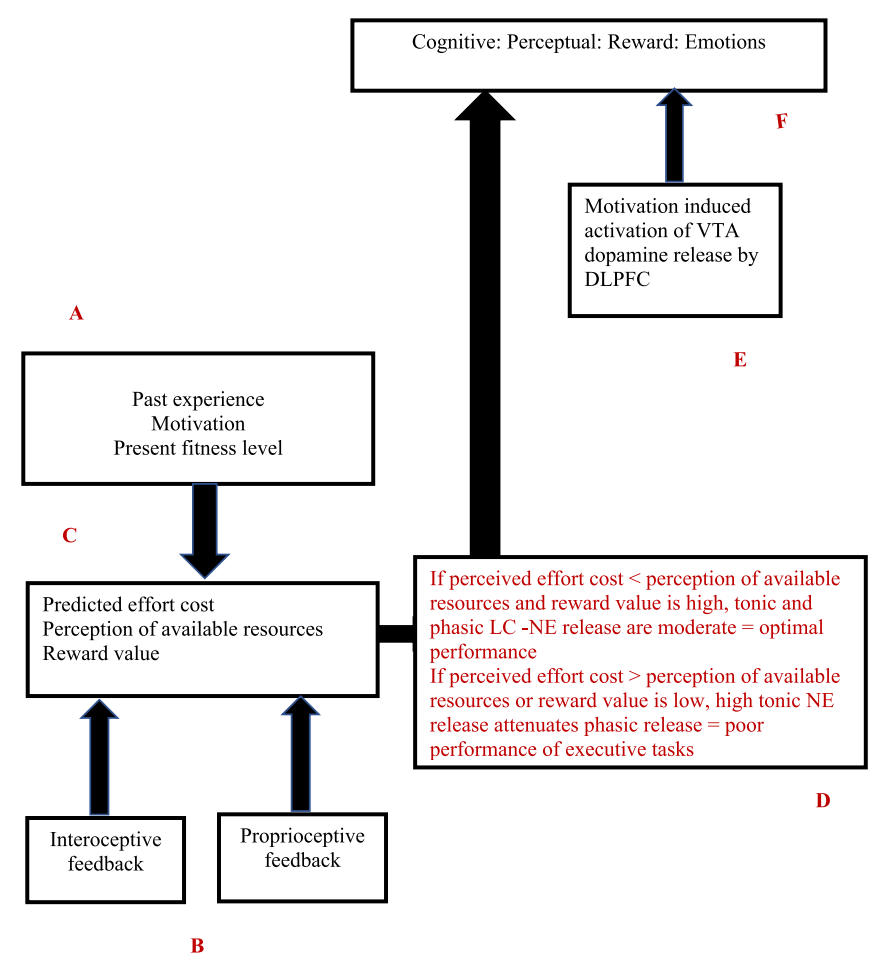

Fig. 2. Overview of the interoception model.

A Psychological factors affecting prediction of effort costs, perception of available resources and reward value.

B Information from small diameter primary afferents, large diameter sensory fibers in skin, muscles and joints, and chemoreceptors and mechanoreceptors in vagal and glossopharyngeal nerves.

C Information from A is evaluated by DLPFC and predicted effort cost is forwarded to the AIC and ACC. Information from B, held in the AIC, ACC and OFC, is compared to the predictions from $\mathbf{A}$, and fed back to the DLPFC for a decision on what action to take.

D The decision depends on comparison of perceived effort costs and expected value of the reward. If available resources are perceived to be sufficient to meet predicted effort costs and the reward is high, the OFC and ACC initiate moderate tonic and phasic release of LC-NE. This is optimal for tasks requiring activation of top-down and/or bottom-up salient stimuli. If the perceived resources are thought to be insufficient to meet the costs or the reward is poor, high tonic release is initiated, which attenuates phasic release. This has an inhibitory effect on tasks requiring activation by salient stimuli but aids tasks requiring switching to alternative S-R pairings or alternative courses of action. E At rest or during low intensity exercise, in motivated individuals, the DLPFC may trigger increased tonic release of dopamine from the VTA, which can result in optimal cognitive performance by inducing moderate tonic and phasic LC-NE release.

F It should be noted that cognition involves interactions with perception, motivation and emotions

ACC anterior cingulate cortex; AIC anterior insula cortex; DLPFC dorsolateral prefrontal cortex; LC-NE locus coeruleus-norepinephrine; OFC orbitofrontal cortex; S-R stimulus-response; VTA ventral tegmental area.

(Craig, 2002). Aston-Jones and Cohen (2005) claim that if the decision is to continue working on the task, the orbitofrontal cortex and anterior cingulate cortex project to the locus coeruleus to induce attenuation of tonic release of norepinephrine to a level that facilitates stimulus-driven phasic release. However, if the decision is that the task is not worthwhile or performance can not be maintained, increased tonic release is triggered, which inhibits phasic release. This favors task disengagement and facilitates tasks which require a switch to dealing with different stimuliresponse requirements or alternative courses of action but inhibits executive functions.

\subsection{Testing the model: implications for future research}

The model incorporates the assertion in the catecholamines hypothesis that moderate intensity exercise induces increased extracellular concentrations of dopamine and norepinephrine, which results in improved cognition compared to that at rest and during low intensity exercise. Our present knowledge level suggests that exercise above the norepinephrine threshold and equivalents induces optimal performance. However, more research is required comparing exercise intensities just below the thresholds with those supra-thresholds. Moreover, the assumption that the thresholds induce changes in tonic and phasic locus coeruleus-norepinephrine release can be examined using pupillometry, EEG to measure P3 amplitude, fMRI and functional near infra-red spectroscopy (fNIRS). Also, the effects of motivation on performance at rest should be compared to cognition during supra-threshold exercise. This could answer the question of whether motivation can result in performance at rest being equal to that during supra-threshold exercise. More testing of the effects of severe exercise on learning/LTM is required, as are studies examining moderate intensity exercise of longduration. However, the model contains areas of research, which have so far been rarely, or never, examined in acute exercise-cognition research, namely motivation, perception of effort costs, and the effects of tonic versus phasic locus coeruleus-norepinephrine release during severe exercise. Suggestions of how this might be done are outlined in the following sub-sections.

\subsubsection{Testing motivation effects}

Motivation should be examined at rest, during moderate and severe exercise. It could be done using subjective report but should also involve some form of objective assessment. Pupillometry can be used to assess dopamine activation in brain regions involved in reward/motivation (Muhammed et al., 2016; Wang, 2015) pre- and/or post-cognitive test. Dopamine is the main neuromodulator in the motivation/reward pathway, although norepinephrine also plays a role (Elliott et al., 2000a, 2000b), therefore this could give us information about motivation especially if it is correlated with subjective assessment. Activation of the motivation/reward pathway could also be examined using PET, fMRI or fNIRS. This would allow for the effect of motivation on the cognitive performance in the at rest condition to be evaluated. It would also be important during severe exercise to determine any effects on phasic and tonic locus coeruleus-norepinephrine release. To determine whether motivation during the at rest cognitive test can induce performance as good as that during moderate intensity exercise, pharmacological administration of dopamine $\mathrm{D}_{\underline{1}}$-receptor and $\alpha_{2 \mathrm{~A}}$-adrenoceptor agonists could be administrated. A cross-over design could be used whereby participants are given the agonists or a placebo and tested cognitively pre- and post-exercise. If moderate exercise in the placebo condition induces better performance than in the pre-test agonists condition, it would suggest that even when highly motivated, one can not perform at rest as well as during or immediately following moderate intensity exercise.

Manipulation of motivation using monetary rewards or competition with others by use of avatars could be useful. The former has been shown to work in cognitive fatigue studies (Carter et al., 2015; Inzlicht et al., 2014). While Corbett et al. (2018) successfully used the latter method in a central fatigue study but, unknown to the participant, the avatar represented their own performance in a previous test. Barwood et al. (2015) successfully utilized pre-exercise motivational self-talk. These and similar strategies could be used to test the effects of motivation.

\subsubsection{Effects of tonic and phasic release of catecholamines during severe} exercise

No studies have directly set out to test the hypothesis that severe exercise induces changes in cognition due to increased tonic release of norepinephrine attenuating phasic release but some inadvertently provide interesting data. Three studies which examined the effect of severe 
exercise on a subsequent flanker task (Kao et al., 2017) or a Go/NoGo task (Kamijo et al., 2004a; Kamijo et al., 2004b), also measured P3 amplitude. The authors demonstrated inhibition of cognitive performance and that P3 amplitude at cessation of the exercise, indicated an increase in tonic locus coeruleus-norepinephrine release and attenuation of phasic release. However, no studies have examined the efficacy of increased tonic release of norepinephrine facilitating switching performance following severe exercise. Although, animal research has shown the benefit of increased tonic locus coeruleus-norepinephrine release on switching tasks (Bondi et al., 2010; Robbins and Roberts, 2007). The use of EEG measures of P3 amplitude or indeed pupillometry measurements could both be very useful in testing the roles of phasic versus tonic locus coeruleus-norepinephrine release following severe exercise and the effects of task type. Similarly, PET, fMRI and fNIRS could provide valuable information. It should be noted, however, that the relationship between P3 amplitude and locus coeruleus-norepinephrine relsase has been questioned (McGowan et al., 2019).

\subsubsection{Testing perception of effort costs and resources available}

Questionnaires could be used to assess perception of effort costs and perception of resource availability. The National Aeronautics and Space Administration-Task Load Index (NASA-TLX) has been used to measure perception of effort cost and has been validated and tested for reliability (Hart and Staveland, 1988). It may be particularly useful when dealing with exercise and cognition as it is multidimensional and measures effort cost using a combination of cognitive and physical effort.

\section{Conclusion}

The catecholamines hypothesis provides a plausible explanation of the processes involved in facilitating cognition during and following moderate intensity exercise, although some clarification concerning the need to reach the norepinephrine threshold or equivalents is required. However, the hypothesis can not explain empirical data regarding the effects of severe exercise on cognition. Modern interpretations of interoception (Craig, 2002; Damasio, 1994) provide a rationale for the acute exercise-cognition interaction and can be presented as a model. During moderate intensity exercise, the afferent interoceptive system and the proprioceptive somatosensory system, through interactions between the anterior insula, anterior cingulate, orbitofrontal and lateral prefrontal cortices, instigate increased tonic release of catecholamines, resulting in increased extracellular concentrations. This results in phasic release of dopamine and norepinephrine, and facilitation of cognitive tasks.

During severe exercise, the interoceptive system initiates further tonic release of catecholamines, which attenuates phasic release and dampens neural activity. However, whether this leads to inhibition of cognition depends on how the individual perceives the interoceptive information concerning perceptions of effort costs and their own motivation level. Interactions between the lateral prefrontal. anterior insula, anterior cingulate, orbitofrontal cortices and the locus coeruleus can maintain tonic release at high levels or lower tonic release (Aston-Jones and Cohen, 2005). Lowering tonic release facilitates phasic release and so maintains cognitive functioning at a level equal to that during moderate intensity exercise. Maintaining high tonic release can aid learning/ LTM and tasks that require switching to new stimuli-response couplings or alternative courses of action. However, performance of tasks requiring phasic catecholamines release will be weakened.

\section{Acknowledgements}

This research did not receive any specific grant from funding agencies in the public, commercial, or not-for-profit sectors.

\section{References}

Alberini, C.M., Cruz, E., Descalzi, G., Bessièrres, B., Gao, V., 2017. Astrocyte glycogen and lactate: new insights into learning and memory mechanisms. Glia 66, 1244-1262.

Albouy, G., Sterpenich, V., Balteau, E., Vandewalle, G., Desseilles, M., Dang-Vu, T., Darsaud, A., Ruby, P., Luppi, P.H., Degueldre, C., Peigneux, P., Luxen, A.,

Maquet, P., 2008. Both the hippocampus and striatum are involved in consolidation of motor sequence memory. Neuron 58, 261-272.

Alexander, G.E., DeLong, M.R., Strick, P.L., 1986. Parallel organization of functionally segregated circuits linking basal ganglia and cortex. Annu. Rev. Neurosci. 9, 357-381.

Arnold, W.P., Mittal, C.K., Katsuki, S., Murad, F., 1977. Nitric oxide activates guanylate cyclase and increases guanosine $3^{\prime}: 5^{\prime}$-cyclic monophosphate levels in various tissue preparations. Proc. Natl. Acad. Sci. U S A. 74, 3203-3207.

Arnsten, A.F.T., 2009. Stress signalling pathways that impair prefrontal cortexstructure and function. Nat. Rev. Neurosci. 10, 410-422.

Arnsten, A.F.T., 2011. Catecholamine influences on dorsolateral prefrontal corticalnetworks. Biol. Psychiatry 69. https://doi.org/10.1016/j. biopsych.2011.01.027.

Arts, F.J.P., Kuipers, H., 1994. The relation between power output, oxygen uptake and heart rate in male athletes. International Journal of Sports Med. 15, 228-231.

Asahara, R., Matsukawa, K., Ishii, K., Liang, N., Endo, K., 2016. The prefrontal oxygenation and ventilatory responses at start of one-legged cycling exercise have relation to central command. J. Appl. Physiol. 121, 1115-1126.

Aston-Jones, G., Cohen, J.D., 2005. An integrative theory of locus coeruleusnorepinephrine function: adaptive gain and optimal performance. Annu. Rev. Neurosci. 28, 403-450.

Aston-Jones, G., Rajkowski, J., Cohen, J., 2000. Locus coeruleus and regulation of behavioral flexibility and attention. Prog Brain Res. 126, 165-182.

Aston-Jones, G., Zhu, Y., Card, J.P., 2004. Numerous GABAergic afferents to locus ceruleus in the pericerulear dendritic zone: possible interneuronal pool. J. Neurosci. 24, 2313-2321.

Audiffren, M., 2009. Acute exercise and psychological functions: a cognitive-energetic approach. In: McMorris, T., Tomporowski, P.D., Audiffren, M. (Eds.), Exercise and Cognitive Function. Wiley, Chichester, pp. 2-53.

Audiffren, M., 2016. The reticular-activating hypofrontality (RAH) model of acute exercise: current data and future perspectives. In: McMorris, T. (Ed.), ExerciseCognition Interaction: Neuroscience Perspectives. Elsevier Academic Press, New York, pp. 69-90.

Bae, S., Masaki, H., 2019. Effects of acute aerobic exercise on cognitive flexibility required during task-switching paradigm. Front Hum. Neurosci. doi. https://doi.org/ 10.3389/fnhum.2019.00260.

Bailey, C.H., Kandel, E.R., Harris, K.M., 2015. Structural components of synaptic plasticity and memory consolidation. Cold Spring Harb. Perspect. Biol. doi. https:// doi.org/10.1101/cshperspect.a021758.

Baker, K.G., Tork, I., Hornung, J.P., Halasz, P., 1989. The human locus coeruleus complex: an immunohistochemical and three dimensional reconstruction study. Exp. Brain Res. 77, 257-270.

Bard, C., Fleury, M., 1978. Influence of imposed metabolic fatigue on visual capacity components. Percept. Motor Skill. 47, 1283-1287.

Barwood, M.J., Corbett, J., Wagstaff, C.R.D., McVeigh, D., Thelwell, R.C., 2015. Improvement of $10-\mathrm{km}$ time-trial cycling with motivational self-talk compared with neutral self-talk. Int. J. Sports Physiol. Perform. 10, 166-171.

Beaver, W.L., Wasserman, K., Whipp, B.J., 1985. Improved detection of lactate threshold during exercise using a log-log transformation. J. Appl. Physiol. 59, 1936-1940.

Bediz, C.S., Oniz, A., Guducu, C., Demirci, E.U., Ogut, H., Gunay, E., Cetinkaya, C., Ozgoren, M., 2016. Acute supramaximal exercise increases the brain oxygenation in relation to cognitive workload. Front. Hum. Neurosci. doi. https://doi.org/10.3389/ fnhum.2016.00174.

Belujon, P., Grace, A.A., 2015. Regulation of dopamine system responsivity and its adaptive and pathological response to stress. Proc. Biol. Sci. https://doi.org/ 10.1098/rspb.2014.2516.

Bergstrom, H.C., Housh, T.J., Zuniga, J.M., Traylor, D.A., Camic, C.L., Lewis, R.W., Schmidt, R.J., Johnson, G.O., 2013. The relationships among critical power determined from a 3-min all-out test, respiratory compensation point, gas exchange threshold and ventilatory threshold. Res. Q. Exerc. Sport 84, 232-238.

Bermejo, J.L., Ribeiro do Couto, B., Marco-Ahulló, A., Villarrasa-Sapiña, I., GarciaMasso, X., 2019. Effects of an incremental maximal endurance exercise stressinduced cortisol on cognitive performance. J. Hum. Sport Exerc. https://doi.org/ 10.14198/jhse.2019.143.13.

Best, J.R., 2010. Effects of physical activity on children's executive function: contributions of experimental research on aerobic exercise. Dev. Rev. 30, 331-551.

Blakemore, S.J., Rees, G., Frith, C.D., 1998. How do we predict the consequences of our actions? A functional imaging study. Neuropsychologia 25, 410-418.

Bliss, T., Lømo, T., 1973. Long-lasting potentiation of synaptic transmission in the dentate area of the anaesthetized rabbit following stimulation of the perforant path. J. Physiol. 232, 331-356.

Bondi, C.O., Jett, J.D., Morilak, D.A., 2010. Beneficial effects of desipramine on cognitive function of chronically stressed rats are mediated by alpha1-adrenergic receptors in medial prefrontal cortex. Prog. Neuro-Psychoph. 34, 913-923.

Bouret, S., Ravel, S., Richmond, B.J., 2012. Complementary neural correlates of motivation in dopaminergic and noradrenergic neurons of monkeys. Front. Behav. Neurosci. doi. https://doi.org/10.3389/fnbeh.2012.00040.

Bromberg-Martin, E.S., Matsumoto, M., Hikosaka, O., 2010. Dopamine in motivational control: rewarding, aversive, and alerting. Neuron. 68, 815-834. 
Brown, D.M.Y., Graham, J.D., Innes, K.I., Harris, S., Flemington, A., Bray, S.R., 2020. Effects of prior cognitive exertion on physical performance: a systematic review and meta-analysis. Sports Med. 50, 497-529.

Burgess, P.W., Wu, H.C., 2013. Rostral prefrontal cortex (Brodmann area 10): metacognition in the brain. In: Stuss, D.T., Knight, R.T. (Eds.), Principles of Frontal Lobe Function, $2^{\text {nd }}$ edition. OUP, New York, pp. 524-534.

Carter, E.C., Kofler, L.M., Forster, D.E., McCullough, M.E., 2015. A series of metaanalytic tests of the depletion effect: Self-control does not seem to rely on a limited resource. J. Exp. Psychol. Gen. 44, 796-815.

Chang, Y.K., Labban, J.D., Gapin, J.I., Etnier, J.L., 2012. The effects of acute exercise on cognitive performance: a meta-analysis. Brain Res. 1453, 87-101.

Chang, Y.K., Chen, F.T., Kuan, G., Wei, G.X., Chu, C.H., Yan, J., Chen, A.G., Hung, T.M., 2019. Effects of acute exercise duration on the inhibition aspect of executive function in late middle-aged adults. Front. Aging Neurosci. doi. https://doi.org/ 10.3389/fnagi.2019.00227.

Chmura, J., Nazar, K., 2010. Parallel changes in the onset of blood lactate accumulation (OBLA) and threshold of psychomotor performance deterioration during incremental exercise after training in athletes. Int. J. Psychophysiol. 75, 287-290.

Chmura, J., Nazar, H., Kaciuba-Uścilko, H., 1994. Choice reaction time during graded exercise in relation to blood lactate and plasma catecholamine thresholds. Int. J. Sports Med. 15, 172-176.

Christensen, M.S., Lundbye-Jensen, J., Geertsen, S.S., Petersen, T.H., Paulson, O.B., Nielsen, J.B., 2007. Premotor cortex modulates somatosensory cortex during voluntary movements without proprioceptive feedback. Nat. Neurosci. 10, 417-419.

Christoff, K., Gabrieli, J.D.E., 2000. The frontopolar cortex and human cognition: Evidence for a rostrocaudal hierarchical organization within the human prefrontal cortex. Psychobiology 28, 168-186.

Coco, M., Di Corrado, D., Calogero, R.A., Perciavalle, V., Maci, T., 2009. Attentional processes and blood lactate levels. Brain Res. 1302, 205-211.

Cole, M.W., Reynolds, J.R., Power, J.D., Repovs, G., Anticevic, A., Braver, T.S., 2013. Multi-task connectivity reveals flexible hubs for adaptive task control. Nat. Neurosci. $16,1348-1355$.

Collardeau, M., Brisswalter, J., Audiffren, M., 2001. Effects of a prolonged run on simple reaction time of well trained runners. Percept. Motor Skill. 93, 679-689.

Cooper, C.J., 1973. Anatomical and physiological mechanisms of arousal with specific reference to the effects of exercise. Ergonomics 16, 601-609.

Corbett, J., White, D.K., Barwood, M.J., Wagstaff, C.R.D., Tipton, M.J., McMorris, T., Costello, J.T., 2018. The effect of head-to-head competition on behavioural thermoregulation, thermophysiological strain and performance during exercise in the heat. Sports Med. 48, 1269-1279.

Craig, A.D., 2002. How do you feel? Interoception: the sense of the physiological condition of the body. Nat. Rev. Neurosci. 3, 655-666.

Craig, A.D., 2006. Physical activity and the neurobiology of interoception. In: Acevedo, E.O., Ekkakakis, P. (Eds.), Psychobiology of Physical Activity. Human Kinetics, Champaign, Il., pp. 15-28

Craig, A.D., 2015. How do you feel? An interoceptive moment with your neurobiological self. Princeton University Press, Ptinceton, NJ.

Craik, F.I.M., Lockhart, R.S., 1972. Levels of processing: a framework for memory research. J. Verb. Learn. Verb. Be. 11, 671-684.

Critchley, H.D., Garfinkel, S.N., 2017. Interoception and emotion. Curr. Opin. Psychol. $17,7-14$.

Critchley, H.D., Harrison, N.A., 2013. Visceral influences on brain and behavior. Neuron. https://doi.org/10.1016/j.neuron.2013.02.008.

Critchley, H.D., Corfield, D.R., Chandler, M.P., Matthias, C.J., Dolan, R.J., 2000. Cerebral correlates of autonomic cardiovascular arousal: a functional neuroimaging investigation in humans. J. Physiol. 523, 259-270.

Damasio, A.R., 1994. Descartes' Error: Emotion Reason and the Human Brain. Putnam, New York.

Davey, C.P., 1973. Physical exertion and mental performance. Ergonomics 16, 595-599.

Davis, J.M., Bailey, S.P., 1996. Possible mechanisms of central nervous system fatigue during exercise. Med. Sci. Sports Exerc. 29, 45-57.

Davranche, K., McMorris, T., 2009. Specific effects of acute moderate exercise on cognitive control. Brain Cogn. 69, 565-570.

Dean, T.L., Perreault, M., Mazzeo, R.S., Horton, T.J., 2003. No effect of menstrual cycle phase on lactate threshold. J. Appl. Physiol. 95, 2537-2543.

Di Bernardi Luft, C., Takase, E., Darby, D., 2009. Heart rate variability and cognitive function: Effects of physical effort. Biol. Psychol. 82, 186-191.

Dietrich, A., 2009. The transient hypofrontality theory and its implications for emotion and cognition. In: McMorris, T., Tomporowski, P.D., Audiffren, M. (Eds.), Exercise and Cognitive Function. Wiley-Blackwell, Chichester, pp. 99-138.

Doya, K., 2000. Complementary roles of basal ganglia and cerebellum in learning and motor control. Curr. Opin. Neurobiol. 10, 732-739.

Du Rietz, E., Barker, A.R., Michelini, G., Rommel, A.S., Vainieri, I.V., Asherson, P., Kuntsi, J., 2019. Beneficial effects of acute high-intensity exercise on electrophysiological indices of attention processes in young adult men. Behav. Brain Res. 359, 474-484.

Duncan, C.C., Kaye, W.H., 1987. Effects of clonidine on event-related potential measures of information proccessing. Electroencephalogr. Clin. Neurophysiol. Suppl. 40 527-531.

Eisenhofer, G., Kopin, I.J., Goldstein, D.S., 2004. Catecholamine metabolism: A contemporary view with implications for physiology and medicine. Pharmacol. Rev. 56, 331-348.

Elliott, R., Dolan, R.J., Frith, C.D., 2000a. Dissociable functions in the medial and lateral orbitofrontal cortex: evidence from human neuroimaging studies. Cereb. Cortex 10, 308-317.
Elliott, R., Friston, K.J., Dolan, R.J., 2000b. Dissociable neural responses in human reward systems. J. Neurosci. 20, 6159-6165.

Ferris, L.T., Williams, J.S., Shen, C., 2007. The effect of acute exercise on serum brainderived neurotrophic factor levels and cognitive function. Med. Sci. Sports Exer. 39, $728-734$.

Féry, Y.-A., Ferry, A., Vom Hofe, A., Rieu, M., 1997. Effect of physical exhaustion on cognitive functioning. Percept. Motor Skill. 84, 291-298.

Finkenzeller, T., Doppelmayr, M., Würth, S., Amesberger, G., 2018. Impact of maximal physical exertion on interference control and electrocortical activity in well-trained persons. Eur. J. Appl. Physiol. 118, 2509-2521.

Floresco, S.B., West, A.R., Ash, B., Moore, H., Grace, A.A., 2003. Afferent modulation of dopamine neuron firing differentially regulates tonic and phasic dopamine transmission. Nat. Neurosci. 6, 968-973.

Fontana, F.E., Mazzardo, O., Mokgothu, C., Furtado, O., Gallagher, J.D., 2009. Influence of exercise intensity on the decision-making performance of experienced and inexperienced soccer players. J. Sport Exerc. Psychol. 31, 135-151.

Gandevia, S.C., 2001. Spinal and supraspinal factors in human muscle fatigue. Physiol. Rev. 81, 1725-1789.

Ghaziri, J., Tucholka, A., Girard, G., Houde, J.C., Boucher, O., Gilbert, G., Descoteaux, M., Lippé, S., Rainville, P., Nguyen, D.K., 2017. The corticocortical structural connectivity of the human insula. Cereb. Cortex 27, 1216-1228.

Gilzenrat, M.S., Nieuwenhuis, S., Jepma, M., Cohen, J.D., 2010. Pupil diameter tracks changes in control state predicted by the adaptive gain theory of locus coeruleus function. Cogn. Affect Behav. Neurosci. 10, 252-269.

Gnegy, M.E., 2012. Catecholamines. In: Brady, S.T., Siegel, G.J., Albers, R.W., PrIce, D.L. (Eds.), Basic Neurochemistry, $8^{\text {th }}$ edition. Elsevier Academic Press, New York, pp. 283-299.

González-Fernández, F., Etnier, J.L., Zabala, M., Sanabria, D., 2017. Vigilance performance during acute exercise. Int. J. Sport Psychol. 48, 435-447.

Gordon, R., Spector, S., Sjoerdsma, A., Udenfriend, S., 1966. Increased synthesis of norepinephrine and epinephrine in the intact rat during exercise and exposure to cold. J. Pharmacol. Exp. Ther. 153, 440-447.

Gorelova, N., Seamans, J.K., Yang, C.R., 2002. Mecahainisms of dopamine activation of faast-spiking interneurons that exert inhibition in rat prefrontal cortex. J. Neurophysiol. 88, 3150-3166.

Grace, A.A., 1991. Phasic versus tonic dopamine release and the modulation of dopamine system responsivity: A hypothesis for the etiology of schizophrenia. Neuroscience. $41,1-24$.

Grace, A.A., Bunney, B.S., 1983. Intracellular and extracellular electrophysiology of nigral dopaminergic neurons-1. Identification and characterization. Neuroscience 10, 301-315.

Green, H.J., Hughson, R.L., Orr, G.W., Ranney, D.A., 1983. Anaerobic threshold, blood lactate, and muscle metabolites in progressive exercise. J. Appl. Physiol. 54, 1032-1038.

Grego, F., Vallier, J.M., Collardeau, M., Bermon, S., Ferrari, P., Candito, M., Bayer, P., Magnié, M.N., Brisswalter, J., 2004. Effects of long duration exercise on cognitive function, blood glucose, and counterregulatory hormones in male cyclists. Neurosci. Lett. 364, 76-80.

Grego, F., Vallier, J.M., Collardeau, M., Rousseu, C., Cremieux, J., Brisswalter, J., 2005. Influence of exercise duration and hydration status on cognitive function during prolonged cycling exercise. Int. J. Sports Med. 26, 27-33.

Grenhoff, J., Nisell, M., Ferré, S., Aston-Jones, G., Svensson, T.H., 1993. Noradrenergic modulation of dopamine cell firing elicited by stimulation of the locus coeruleus in the rat. J. Neural Transm.-Gen. 93, 11-25.

Griffin, É.W., Mullally, S., Foley, C., Warmington, S.A., O'Mara, S.M., Kelly, Á.M., 2011. Aerobic exercise improves hippocampal function and increases BDNF in the serum of young adult males. Physiol. Behav 104, 934-941.

Gu, X., Hof, P.R., Friston, K.J., Fan, J., 2013. Anterior insular cortex and emotional awareness. J. Comp. Neurol. 521, 3371-3388.

Halliday, G.W., Li, Y.W., Joh, T.H., Cotton, R.G.H., Howe, P.R.C., Geffen, L.B., Blessing, W.W., 1988. Distribution of monoamine-synthesizing neurons in the human medulla oblongata. J.Comp. Neurol. 273, 301-317.

Halliday, R., Naylor, H., Brandeis, B., Callaway, E., Yano, L., Herzig, K., 1994. The effect of D-amphetamine, clonidine, and yohimbine on human information processing. Psychophysiology. 31, 331-337.

Hart, S.G., Staveland, L.E., 1988. Development of NASA-TLX (Task Load Index): results of empirical and theoretical research. In: Hancock, P.A., Meshkati, N. (Eds.), Human Mental Workload. North Holland Press, Amsterdam, pp. 139-183.

Hashimoto, T., Tsukamoto, H., Takenaka, S., Olesen, N.D., Petersen, L.G., Sørensen, H., Nielsen, H.B., Secher, N.H., Ogoh, S., 2018. Maintained exercise-enhanced brain executive function related to cerebral lactate metabolism in men. FASEB J. 32, $1417-1427$.

Hawkins, R.D., Kandel, E.R., Siegelbaum, S.A., 1993. Learning to modulate transmitter release: themes and variations in synaptic plasticity. Annu. Rev. Neurosci. 16, 625-665.

Hawkins, R.D., Son, H., Arancio, O., 1998. Nitric oxide as a retrograde messenger during long-term potentiation in hippocampus. Prog. Brain Res. 118, 155-172.

Hill, M., Walsh, S., Talbot, C., Price, M., Duncan, M., 2019. Exercise intensity-dependent effects of arm and leg-cycling on cognitive performance. PLoS One doi. https://doi. org/10.1371/journal.pone.0224092.

Hilty, L., Jäncke, L., Luechinger, R., Boutellier, U., Lutz, K., 2011. Limitation of physical performance in a muscle fatiguing handgrip exercise is mediated by thalamo-insular activity. Hum. Brain Mapp. 32, 2151-2160.

Hodgetts, V., Coppack, S.W., Frayn, K.N., Hockaday, T.D.R., 1991. Factors controlling fat mobilization from human subcutaneous adipose-tissue during exercise. J. Appl. Physiol. 71, 445-451. 
Holloway, B.B., Stornetta, R.L., Bochorishvili, G., Erisir, A., Viar, K.E., Guyenet, P.G., 2013. Monosynaptic glutamatergic activation of locus coeruleus and other lower brainstem noradrenergic neurons by the C1 cells in mice. J. Neurosci. 33, 18792-18805.

Holroyd, C.B., Coles, M.G.H., 2002. The neural basis of human error processing: reinforcement learning, dopamine, and the error-related negativity. Psychol. Rev. 109, 679-709.

Horvitz, J.C., 2009. Stimulus-response and response-outcome learning mechanisms in the striatum. Behav. Brain Res. 199, 129-140.

Hosp, J.A., Coenen, V.A., Rijntjes, M., Egger, K., Urbach, H., Weiller, C., Reisert, M., 2019. Ventral tegmental area connections to motor and sensory cortical fields in humans. Brain Struct. Funct. 224, 2839-2855.

Hsieh, S.S., Wang, C.J., Wu, C.T., Chang, Y.K., Hung, T.M., 2018. Acute exercise facilitates the N450 inhibition marker and P3 attention marker during Stroop Test in young and older adults. J. Clin. Med. https://doi.org/10.3390/jcm7110391.

Hu, D., Cao, P., Thiels, E., Chu, C.T., Wu, G.-Y., Oury, T.D., Klann, E., 2007. Hippocampal long-term potentiation, memory, and longevity in mice that overexpress mitochondrial superoxide dismutase. Neurobiol. Learn. Mem. 87, 372-384.

Hull, C., 1943. Principles of Behavior. Appleton-Century-Crofts, New York.

Humphreys, M.S., Revelle, W., 1984. Personality, motivation, and performance: a theory of the relationship between individual differences and information processing. Psychol. Rev. 91, 153-184.

Hyodo, K., Dan, I., Suwabe, K., Kyutoku, Y., Yamada, Y., Akahori, M., Byun, K., Kato, M., Soya, H., 2012. Acute moderate exercise enhances compensatory brain activation in older adults. Neurobiol. Aging 33, 2621-2632.

Inzlicht, M., Schmeichel, B.J., Macrae, C.N., 2014. Why self-control seems (but may not be) limited. Trends Cogn. Sci. 18, 127-133.

Isaacs, L.D., Pohlman, R.L., 1991. Effects of exercise intensity on an accompanying timing task. J. Hum Movement Stud. 20, 123-131.

Ishii, K., Liang, N., Asahara, R., Takahashi, M., Matsukawa, K., 2018. Feedforward- and motor effort-dependent increase in prefrontal oxygenation during voluntary onearmed cranking. J. Physiol. 596, 5099-5118.

Ji, Y., Pang, P.T., Feng, L., Lu, B., 2005. Cyclic AMP controls BDNF-induced TrkB phosphorylation and dendritic spine formation in mature hippocampal neurons. Nat. Neurosci. 8, 164-172.

Jones, A.M., Vanhatalo, A., 2017. The 'Critical Power' concept: applications to sports performance with a focus on intermittent high-intensity exercise. Sports Med. 47, S65-S78.

Joyce, J., Graydon, J., McMorris, T., Davranche, K., 2009. The time course effect of moderate intensity exercise on response execution and response inhibition. Brain Cogn. 71, 14-19.

Kahneman, D., 1973. Attention and Effort. Prentice Hall, Englewood Cliffs, NJ.

Kamijo, K., Nishihira, Y., Hatta, A., Kaneda, T., Kida, T., Higashiura, T., Kuroiwa, K., 2004a. Changes in arousal level by differential exercise intensity. Clin. Neurophysiol. 115, 2693-2698.

Kamijo, K., Nishihira, Y., Hatta, A., Kaneda, T., Wasaka, T., Kida, T., Kuroiwa, K., 2004b. Differential influences of exercise intensity on information processing in the central nervous system. Eur. J. Appl. Physiol. 92, 305-311.

Kao, S.-C., Westfall, D.R., Soneson, J., Gurd, B., Hillman, C.H., 2017. Comparison of the acute effects of high-intensity interval training and continuous aerobic walking on inhibitory control. Psychophysiology 54, 1335-1345.

Kao, S.-C., Cadenas-Sanchez, C., Shigeta, T.T., Walk, A.M., Chang, Y.-K., Pontifex, M.B., Hillman, C.H., 2019. A systematic review of physical activity and cardiorespiratory fitness on P3b. Psychophysiology. https://doi.org/10.1111/psyp.13425.

Kashihara, K., Nakahara, Y., 2005. Short-term effect of physical exercise at lactate threshold on choice reaction time. Percept. Motor Skill. 100, 275-291.

Kitahama, K., Pearson, J., Denoroy, L., Kopp, N., Ulrich, J., Maeda, G., Jouvet, M., 1985. Adrenergic neurons in human brain demonstrated by immunohistochemistry with antibodies to phenyl-ethanolamine-N-methyltransferase (PNMT): discovery of a new group in the nucleus tractus solitariius. Neurosci. Lett. 53, 303-308.

Koechlin, E., Hyafil, A., 2007. Anterior prefrontal function and the limits of human decision-making. Science 318, 594-598.

Kujach, S., Byun, K., Hyodo, K., Suwabe, K., Fukuie, T., Laskowski, R., Dan, I., Soya, H., 2018. A transferable high-intensity intermittent exercise improves executive performance in association with dorsolateral prefrontal activation in young adults. NeuroImage 169, 117-125.

Labban, J.D., Etnier, J.L., 2018. The effect of acute exercise on encoding and consolidation of long-term memory. J. Sport Exerc. Psychol. 40, 336-342.

Lambourne, K., Tomporowski, P., 2010. The effect of exercise-induced arousal on cognitive task performance: a meta-regression analysis. Brain Res. 1341, 12-24.

Lefferts, W.J., DeBlois, K.P., White, C.N., Hefferenan, K.S., 2019. Effects of acute aerobic exercise on cognition and constructs of decision-making in adults with and without hypertension. Front. Aging Neurosci. doi. https://doi.org/10.3389/ fnagi.2019.00041.

Ligeza, T.S., Maciejczyk, M., Kałamała, P., Szygula, Z., Wyczesany, M., 2018. Moderateintensity exercise boosts the N2 neural inhibition marker: A randomized and counterbalanced ERP study with precisely controlled exercise intensity. Biol. Psychol. 135, 170-179.

Marcora, S., 2009. Perception of effort during exercise is independent of afferent feedback from skeletal muscles, heart, and lungs. J. Appl. Physiol. 106, 2060-2062.

Martin, P.G., Weerakkody, N., Gandevia, S.C., Taylor, J.L., 2008. Group III and IV muscle afferents differentially affect the motor cortex and motoneurones in humans. J. Physiol. 586, 1277-1289.

Mason, J.W., Hartley, L.H., Kotchen, T.A., Mougey, E.H., Ricketts, P.T., Jones, L.G., 1973. Plasma cortisol and norepinephrine responses in anticipation of muscular exercise. Psychosom. Med. 35, 406-414.
Masters, R.S., Poolton, J.M., Maxwell, J.P., Raab, M., 2008. Implicit motor learning and complex decision making in time-constrained environments. J. Mot. Behav. 40, 71-79.

Mather, M., Huang, R., Clewett, D., Nielsen, S.E., Velasco, R., Tu, K., Han, S., Kennedy, B. L., 2020. Isometric exercise facilitates attention to salient events in women via the noradrenergic system. NeuroImage doi. https://doi.org/10.1016/j. neuroimage.2020.116560.

Matsukawa, K., Ishii, K., Liang, N., Endo, K., Ohtani, R., Nakamoto, T., Wakasugi, R., Kadowaki, A., Komine, H., 2015. Increased oxygenation of the cerebral prefrontal cortex prior to the onset of voluntary exercise in humans. J. Appl. Physiol. 119, $452-462$.

Mazzeo, R.S., Marshall, P., 1989. Influence of plasma catecholamines on the lactate threshold during graded exercise. J. Appl. Physiol. 67, 1319-1322.

McGowan, A.L., Chandler, M.C., Brascamp, J.W., Pontifex, M.B., 2019. Pupillometric indices of locus-coeruleus activation are not modulated following single bouts of exercise. Int. J. Psychophysiol. 140, 41-52.

McMorris, T., 2009. Exercise and cognitive function: a neuroendocrinological approach. In: McMorris, T., Tomporowski, P.D., Audiffren, M. (Eds.), Exercise and Cognitive Function. Wiley, Chichester, pp. 54-98.

McMorris, T., 2016a. History of research into the acute exercise-cognition interaction: a cognitive psychology approach. In: McMorris, T. (Ed.), Exercise-Cognition Interaction: Neuroscience Perspectives. Elsevier Academic Press, New York, pp. 1-28.

McMorris, T., 2016b. Developing the catecholamines hypothesis for the acute exercisecognition interaction in humans: lessons from animal studies. Physiol. Behav. 165, 291-299.

McMorris, T., 2020. Cognitive fatigue effects on physical performance: The role of interoception. Sports Med. https://doi.org/10.1007/s40279-020-01320-w.

McMorris, T., Graydon, J., 1996a. The effect of exercise on the decision-making performance of experienced and inexperienced soccer players. Res. Q. Exercise Sport. 67, 109-114.

McMorris, T., Graydon, J., 1996b. Effect of exercise on soccer decision-making tasks of differing complexities. J. Hum. Movement Stud. 30, 177-193.

McMorris, T., Graydon, J., 1997. The effect of exercise on cognitive performance in soccer-specific tests. J. Sport Sci. 15, 459-468.

McMorris, T., Hale, B.J., 2012. Differential effects of differing intensities of acute exercise on speed and accuracy of cognition: a meta-analytical investigation. Brain Cogn. 80, 338-351.

McMorris, T., Hale, B.J., 2015. Is there an acute exercise-induced physiological/ biochemical threshold which triggers increased speed of cognitive functioning? A meta-analytic investigation. J. Sport Health Sci. 4, 4-13.

McMorris, T., Keen, P., 1994. Effect of exercise on simple reaction times of recreational athletes. Percept. Motor Skill. 78, 123-130.

McMorris, T., Myers, S., MacGillivary, W.W., Sexsmith, J.R., Fallowfield, J., Graydon, J., Forster, D., 1999. Exercise, plasma catecholamine concentration and decisionmaking performance of soccer players on a soccer-specific test. J. Sport Sci. 17, 667-676.

McMorris, T., Delves, S., Sproule, J., Lauder, M., Hale, B., 2005a. Incremental exercise, perceived task demands and performance of a whole body motor task. Br. J. Sport. Med. 39, 537-541.

McMorris, T., Hill, C., Sproule, J., Potter, J., Swain, J., Hobson, G., Holder, T., 2005b. Supra-maximal effort and reaction and movement times in a non-compatible response time task. J. Sport. Med. Phys. Fit. 45, 127-133.

McMorris, T., Collard, K., Corbett, J., Dicks, M., Swain, J.P., 2008. A test of the catecholamines hypothesis for an acute exercise-cognition interaction. Pharmacol. Biochem. Behav. 89, 106-115.

McMorris, T., Davranche, K., Jones, G., Hall, B., Minter, C., 2009. Acute incremental exercise, performance of a central executive task, and sympathoadrenal system and hypothalamic-pituitary-adrenal axis activity. Int. J. Psychophysiol. 73, 334-340.

McMorris, T., Turner, A., Hale, B.J., Sproule, J., 2016. Beyond the catecholamines hypothesis for an acute exercise-cognition interaction: a neurochemical perspective. In: McMorris, T. (Ed.), Exercise-Cognition Interaction: Neuroscience Perspectives. Elsevier Academic Press, New York, pp. 65-104.

McMorris, T., Barwood, M., Corbett, J., 2018a. Central fatigue theory and endurance exercise: Toward an interoceptive model. Neurosci. Biobehav. Rev. 93, 93-197.

McMorris, T., Barwood, M., Hale, B.J., Dicks, M., Corbett, J., 2018b. Cognitive fatigue effects on physical performance A systematic review and meta-analysis. Physiol. Behav. 188, 103-107.

Meyer, T., Foude, O., Scharhag, J., Urhausen, A., Kindermann, W., 2004. Is lactic acidosis a cause of exercise induced hyperventilation at the respiratory compensation point? Br. J. Sports Med. 38, 622-625.

Mochizuki, Y., Oishi, M., Takasu, T., 1998. Correlations between P300 components and neurotransmitters in the cerebrospinal fluid. Clin. Electroencephalogr. 29, 7-9.

Muhammed, K., Manohar, S., Ben Yehuda, M., Chong, T.T.-J., Tofaris, G., Lennox, G.M., Hu, M., Husain, M., 2016. Reward sensitivity deficits modulated by dopamine are associated with apathy in Parkinson's disease. Brain 139, 2706-2721.

Murphy, P.R., Robertson, I.H., Bolsters, J.H., O'Connell, R.G., 2011. Pupillometry and P3 index the locus coeruleus-noradrenergic arousal function in humans. Psychophysiology 48, 1532-1543.

Murphy, P.R., O'Connell, R.G., O’Sullivan, M., Robertson, I.H., Bolsters, J.H., 2014. Pupil diameter covaries with BOLD activity in human Locus Coeruleus. Hum. Brain Mapp. 35, 4140-4154.

Nee, D.E., D'Esposito, M., 2016. The hierarchical organization of the lateral prefrontal cortex. Elife doi. https://doi.org/10.7554/eLife.12112.

Newsholme, E.A., Acworth, I.N., Blomstrand, E., 1987. Amino acids, brain neurotransmitters and a functional link between muscle and brain that is important 
in sustained exercise. In: Benzi, G. (Ed.), Advances in Biochemistry. John Libbey, London, pp. 127-133.

Noakes, T.D., St. Clair Gibson, A., Lambert, E.V., 2004. From catastrophe to complexity: a novel model of integrative central neural regulation of effort and fatigue during exercise in humans. Br. J. Sports Med. 38, 511-514.

Peaston, R.T., Weinkove, C., 2004. Measurement of catecholamines and their metabolites. Ann. Clin. Biochem. 41, 17-38.

Pessoa, L., Medina, L., Hof, P.R., Desfills, E., 2019. Neural architecture of the vertebrate brain: implications for the interaction between emotion and cognition. Neurosci. Biobehav. Rev. 107, 296-312.

Peyrin, L., Pequignot, J.M., Lacour, J.R., Fourcade, J., 1987. Relationships between catecholamine or 3-methoxy 4-hydroxy phenylglycol changes and the mental performance under submaximal exercise in man. Psychopharmacology 93, 188-192.

Poldrack, R.A., Sabb, F.W., Foerde, K., Tom, S.M., Asarnow, R.F., Bookheimer, S.Y., Knowlton, B.J., 2005. The neural correlates of motor skill automaticity. J. Neurosci. 25, 5356-5364.

Chacko, S.C., Quinzi, F., De Fano, A., Bianco, V., Mussini, E., Berchicci, M., Perri, R.L., Di Russo, F., 2019. A single bout of vigorous-intensity aerobic exercise affects reactive, but not proactive cognitive brain functions. Int. J. Psychophysiol. 147, 233-243.

Rajkowski, J., Kubiak, P., Aston-Jones, G., 1994. Locus coeruleus activity in monkey: phasic and tonic changes are associated with altered vigilance. Brain Res. Bull. 35, 607-616.

Ranjbar-Slamloo, Y., Fazlali, Z., 2020. Dopamine and noradrenaline in the brain; Overlapping or dissociate functions? Front. Mol. Neurosci. doi. https://doi.org/ 10.3389/fnmol.2019.00334.

Rasmussen, P., Brassard, P., Adser, H., Pedersen, M.V., Leick, L., Hart, E., Secher, N.H., Pedersen, B.K., Pilegaard, H., 2009. Evidence for release of brain-derived neurotrophic factor from the brain during exercise. Exp. Physiol. 94, 1062-1069.

Reber, P.J., Squire, L.R., 1994. Parallel brain systems for learning with and without awareness. Learn. Mem. 1, 217-229.

Reimer, J., McGinley, M.J., Liu, Y., Rodenkirch, C., Wang, Q., David, A., McCormick, D. A., Tolias, A.S., 2016. Pupil fluctuations track rapid changes in adrenergic and cholinergic activity in cortex. Nat. Commun. https://doi.org/10.1038/ ncomms13289.

Reis, D.J., Fuxe, K., 1968. Depletion of noradrenaline in the brainstem neurons during sham rage behaviour produced by acute brainstem transmission in cat. Brain Res. 7 , 448-451.

Reis, D.J., Fuxe, K., 1969. Brain norepinephrine: evidence that neuronal release is essential for sham rage behavior following brainstem transection in the cat. Proc. Natl. Acad. Sci. 84, 108-112.

Reznikoff, G.A., Manaker, S., Rhodes, C.H., Winokur, A., Rainbow, T.C., 1986. Localization and quantification of Beta-Adrenergic receptors in human brain. Neurology 36, 1067-1073.

Rinaman, L., 2011. Hindbrain noradrenergic A2 neurons: diverse roles in autonomic, endocrine, cognitive, and behavioral functions. Am. J. Physiol. Regul. Integr. Comp. Physiol. 300, R222-R235.

Robbins, T.W., Roberts, A.C., 2007. Differential regulation of fronto-executive function by the monoamines and acetylcholine. Cereb. Cortex 17, i151-i160.

Robertson, C.V., Marino, F.E., 2016. A role for the prefrontal cortex in exercise tolerance and termination. J. Appl. Physiol. 120, 464-466.

Samuels, E.R., Szabadi, E., 2008. Functional neuroanatomy of the noradrenergic locus coeruleus: its roles in the regulation of arousal and autonomic function Part II: Physiological and pharmacological manipulations and pathological alterations of locus coeruleus activity in humans. Curr. Neuropharmacol. 6, 254-285.

Sanders, A.F., 1983. Towards a model of stress and human performance. Acta Psychol. 53, 61-97.

Saper, C.B., Sorrentino, D.M., German, D.C., de Lacalle, S., 1991. Medullary catecholaminergic neurons in the normal human brain and in Parkinson's disease. Ann. Neurol. 29, 577-584.

Binder, D.K., Scharfman, H.E., 2004. Brain-derived neurotrophic factor. Growth Factors $22,123-131$.

Schneider, D.A., McLellan, T.M., Gass, G.C., 2000. Plasma catecholamine and blood lactate responses to incremental arm and leg exercise. Med. Sci. Sports Exerc. 32, 608-613.

Schoenbaum, G., Roesch, M.R., Stalnaker, T.A., Takahashi, Y.K., 2009. A new perspective on the role of the orbitofrontal cortex in adaptive behaviour. Nat. Rev. Neurosci. 10, 885-892.

Shadmehr, R., Krakauer, J.W., 2008. A computational neuroanatomy for motor control. Exp. Brain Res. 185, 359-381.

Sharma, Y., Xu, T., Graf, W.M., Fobbs, A., Sherwood, C.C., Patrick, R., Hof, P.R., Allman, J.M., Kebreten, F., Manaye, K.F., 2010. Comparative anatomy of the locus coeruleus in humans and non-human primates. J. Comp. Neurol. https://doi.org/ 10.1002/cne.22249.

Lovero, K.L., Simmons, J.L., Aron, M.P., Paulus, A.N., 2009. Anterior insular cortex anticipates impending stimulus significance. NeuroImage 45, 976-983.

Sjöberg, H., 1980. Physical fitness and mental performance during and after work. Ergonomics. 23, 977-985.

Smith, M., Tallis, J., Miller, A., Clarke, N.D., Guimarães-Ferreira, L., Duncan, M.J., 2016. The effect of exercise intensity on cognitive performance during short duration treadmill running. J. Hum. Kinet. 51, 27-35.

Soutschek, A., Kang, P., Ruff, C.C., Hare, T.A., Tobler, P.N., 2018. Brain stimulation over the frontopolar cortex enhances motivation to exert effort for reward. Biol. Psychiatry 84, 38-45.

Spielberg, J.M., Miller, G.A., Warren, S.L., Engels, A.S., Crocker, L.D., Banich, M.T., Sutton, B.P., Heller, W., 2012. A brain network instantiating approach and avoidance motivation. Psychophysiology 49, 1200-1214.
Straube, T., Korz, V., Balschun, D., Frey, J.U., 2003. Requirement of Beta-Adrenergic receptor activation and protein synthesis for LTP-reinforcement by novelty in rat dentate gyrus. J. Physiol. 552, 953-960.

Sudo, M., Komiyama, T., Aoyagi, R., Nagamatsu, T., Higaki, Y., Ando, S., 2017. Executive function after exhaustive exercise. Eur. J. Appl. Physiol. 117, 2029-2038.

Sutton, S., Braren, M., Zubin, J., John, E.R., 1965. Evoked-potential correlates of stimulus uncertainty. Science 150, 1187-1188.

Suzuki, A., Stern, S.A., Bozdagi, O., Huntley, G.W., Walker, R.H., Magistretti, P.J., Alberini, C.M., 2011. Astrocyte-neuron lactate transport is required for long-term memory formation. Cell 144, 810-823.

Tanaka, L.Y., Bechara, L.R., dos Santos, A.M., Jordão, C.P., de Sousa, L.G., Bartholomeu, T., Ventura, L.I., Laurindo, F.R., Ramires, P.R., 2015. Exercise improves endothelial function: a local analysis of production of nitric oxide and reactive oxygen species. Nitric Oxide 45, 7-14.

Tempest, G.D., Davranche, K., Brisswalter, J., Perrey, S., Radel, R., 2017. The differential effects of prolonged exercise upon executive function and cerebral oxygenation. Brain Cogn. 113, 133-141.

Thomson, K., Watt, A., Liukkonen, J., 2009. Differences in ball sports athletes speed discrimination skills before and after exercise induced fatigue. J. Sports Sci. Med. 8, $259-264$.

Tomporowski, P.D., 2003. Effects of acute bouts of exercise on cognition. Acta Psychol. 112, 297-324.

Tomporowski, P.D, Ellis, N.R., Stephens, R., 1987. The immediate effects of strenuous exercise on free-recall memory. Ergonomics 30, 121-129.

Tonegawa, S., Pignatelli, M., Roy, D.S., Ryan, T.J., 2015. Memory engram storage and retrieval. Curr. Opin. Neurobiol. 35, 101-109.

Tritsch, N.X., Sabatini, B.L., 2012. Dopaminergic modulation of synaptic transmission in cortex and striatum. Neuron 76, 33-50.

Usher, M., Cohen, J.D., Servan-Schreiber, D., Rajkowski, J., Aston-Jones, G., 1999. The role of locus coeruleus in the regulation of cognitive performance. Science 283, 549-554.

Van Cutsem, J., Marcora, S., De Pauw, K., Bailey, S., Meeusen, R., Roelands, B., 2017. The effects of mental fatigue on physical performance: a systematic review. Sports Med. 47, 1569-1588.

Varazzani, C., San-Galli, A., Gilardeau, S., Bouret, S., 2015. Noradrenaline and dopamine neurons in the reward/effort trade-off: a direct electrophysiological comparison in behaving monkeys. J. Neurosci. 35, 7866-7877.

Vonk, M., Wikkerink, S., Regan, K., Middleton, L.E., 2019. Similar changes in executive function after moderate resistance training and loadless movement. PLOS ONE. https://doi.org/10.1371/journal.pone.0212122.

Wang, C.-A., Munoz, D.P., 2015. A circuit for pupil orienting responses: implications for cognitive modulation of pupil size. Curr. Opin. Neurobiol. 33, 134-140.

Wang, M., Ramos, B.P., Paspalas, C.D., Shu, Y., Simen, A., Duque, A., Vijayraghavan, S., Brennan, A., Dudley, A., Nou, E., Mazer, J.A., McCormick, D.A., Arnsten, A.F.T., 2007. $\alpha 2$ A-Adrenoceptors strengthen working memory networks by inhibiting cAMP-HCN channel signaling in prefrontal cortex. Cell 129, 397-410.

Waterhouse, E.G., Xu, B., 2009. New insights into the role of brain-derived neurotrophic factor in synaptic plasticity. Mol. Cell. Neursci. 42, 81-89.

Tharp, J.A., Wendelken, C., Mathews, C.A., Marco, E.J., Schreier, H., Bunge, S.A., 2015. Tourette syndrome: Insights from measures of cognitive control, eyeblink rate, and pupil diameter. Front. Psychiatry. https://doi.org/10.3389/fpsyt.2015.00095.

Weng, T.B., Pierce, G.L., Darling, W.G., Falk, D., Magnotta, V.A., Voss, M.W., 2017. The acute effects of aerobic exercise on the functional connectivity of human brain networks. Brain Plast. 2, 171-190.

Wickens, J.R., Horvitz, J.C., Costa, R.M., Killcross, S., 2007. Dopaminergic mechanisms in actions and habits. J. Neurosci. 27, 8181-8183.

Williamson, J.W., Nobrega, A.C., McColl, R., Mathews, D., Winchester, P., Friberg, L., Mitchell, J.H., 1997. Activation of the insular cortex during dynamic exercise in humans. J. Physiol. 503, 277-283.

Williamson, J.W., McColl, R., Mathews, D., Ginsburg, M., Mitchell, J.H., 1999. Activation of the insular cortex is affected by the intensity of exercise. J. Appl. Physiol. 87, 1213-1219.

Williamson, J.W., McColl, R., Mathews, D., Mitchell, J.H., Raven, P.B., Morgan, W.P., 2001. Hypnotic manipulation of effort sense during dynamic exercise: cardiovascular responses and brain activation. J. Appl. Physiol. 90, 1392-1399.

Williamson, J.W., McColl, R., Mathews, D., Mitchell, J.H., Raven, P.B., Morgan, W.P., 2002. Brain activation by central command during actual and imagined handgrip under hypnosis. J. Appl. Physiol. 92, 1317-1324.

Winneke, A.H., Hübner, L., Godde, B., Voelcker-Rehage, C., 2019. Moderate cardiovascular exercise speeds up neural markers of stimulus evaluation during attentional control processes. J. Clin. Med. https://doi.org/10.3390/jcm8091348.

Winter, B., Breitenstein, C., Mooren, F.C., Voelker, K., Fobker, M., Lechtermann, A., Krueger, K., Fromme, A., Korsukewitz, C., Floel, A., Knecht, S., 2007. High impact running improves learning. Neurobiol. Learn. Mem. 87, 597-609.

Wohlwend, M., Olsen, A., Håberg, A.K., Palmer, H.S., 2017. Exercise intensity-dependent effects on cognitive control function during and after acute treadmill running in young healthy adults. Front. Psychol. doi. https://doi.org/10.3389/ fpsyg.2017.00406.

Wu, C.H., Karageorghis, C.I., Wang, C.C., Chu, C.H., Kao, S.C., Hung, T.M., Chang, Y.K., 2019. Effects of acute aerobic and resistance exercise on executive function: an ERP study. J. Sci. Med. Sport. 22, 1367-1372.

Yamada, K., Nabeshima, T., 2003. Brain-derived neurotrophic factor/TrkB signaling in memory processes. J. Pharmacol. Sci. 91, 267-270. 
Yamamoto, Y., Hughson, R.L., Yamamoto, Y., 1992. Autonomic Nervous System responses to exercise in relation to ventilatory threshold. Chest 101, 206S-210S. Yang, J., Li, P., 2012. Brain networks of explicit and implicit learning. PLoS ONE. https://doi.org/10.1371/journal.pone.0042993.
Yerkes, R.M., Dodson, J.D., 1908. The relation of strength of stimulus to the rapidity of habit formation. J. Comp. Neurol. PsychoL. 18, 459-482. 